\title{
Numerical Simulation Study on Lateral Displacement of Pile Foundation and Construction Process under Stacking Loads
}

\author{
Yan-yan Cai, ${ }^{1,2}$ Bing-xiong Tu, ${ }^{1}$ Jin Yu ${ }^{D},{ }^{1}$ Yao-liang Zhu, ${ }^{1}$ and Jian-feng Zhou ${ }^{1}$ \\ ${ }^{1}$ Fujian Engineering Technology Research Center for Tunneling and Urban Underground Space, Huaqiao University, \\ Xiamen 361021, China \\ ${ }^{2}$ State Key Laboratory of Geohazard Prevention and Geoenvironment Protection, Chengdu University of Technology, \\ Chengdu 610059, China
}

Correspondence should be addressed to Jin Yu; bugyu0717@163.com

Received 16 January 2018; Accepted 18 February 2018; Published 21 March 2018

Academic Editor: Changzhi Wu

Copyright (C) 2018 Yan-yan Cai et al. This is an open access article distributed under the Creative Commons Attribution License, which permits unrestricted use, distribution, and reproduction in any medium, provided the original work is properly cited.

Lateral displacement of pile foundation is crucial to the safety of an overall structure. In this study, a numerical simulation on the lateral displacement of pile foundation under stacking loads was conducted to determine its relation with different influencing factors. Simulation results demonstrated that stacking loads at the pile side mostly influence the lateral displacement of pile foundation. The lateral displacement of pile foundation increases by one order of magnitude when the stacking loads increase from $100 \mathrm{kPa}$ to $300 \mathrm{kPa}$. Other influencing factors are less important than stacking loads. Lateral displacements of the pile body and at the pile top can be reduced effectively by increasing the deformation modulus of surface soil mass, reducing the thickness of soft soil, and expanding pile diameter. Our analysis indicates that a nonlinear relationship exists between the lateral displacement at the pile top and the pile diameter. The lateral resistance of the pile body can be enhanced by coupling the stacking load along piles and the axial force at the pile top. An actual large-scale engineering project was chosen to simulate the effects of postconstructed embankment on lateral displacement and axial force of bridge pile foundation under different construction conditions and to obtain the lateral displacement of the pile body and the negative frictional resistance caused by soft soil compression under stacking loads. On the basis of the calculated results, engineering safety and stability were evaluated, and a guide for the design and construction was proposed.

\section{Introduction}

Pile foundations in bridge, housing construction, and wharf construction engineering mainly bear axial loads. However, pile foundation is inevitably affected by the lateral movement of soil mass in actual construction and use due to excavation, current scouring, adjacent stacking loads, or other reasons, according to Liang et al. [1] and Poulos [2]. Engineering accidents might occur if such influences are not considered thoroughly. Moreover, the expected goal cannot be achieved if the horizontal resistance of pile foundation, which is set to maintain soil stability in some high embankment or slope engineering, is inadequate. Such problems show that studying the responses of pile foundation under lateral movement of soil mass is important. To discuss these problems, scholars have conducted numerous theoretical and experimental studies and applied breakthroughs in engineering. For example, the slope stability problem can be designed by the ultimate equilibrium method proposed by Ito et al. [3]. Horizontal force applied on pile foundation was calculated by using the theoretical equation deduced by Ito and Matsui [4] on the basis of plastic displacement theory. Considering the complexity and diversity of actual engineering, scholars have reported many studies on the horizontal resistance of pile foundation. Chen and Poulos [5] studied the responses of vertical piles under horizontal movement of soil mass by using the simplified boundary element. Goh et al. [6] analyzed the responses of single pile to embankment-induced lateral movement of soil mass. Ashour and Norris [7] analyzed the effects of the bending rigidity of pile body, pile section shape, pile interval, and soil layers on the lateral resistance of pile foundation by using the stress wedge model formula. On the 
basis of the flexural differential equation of elastic piles and the pile-soil interaction spring model of Winkler, Liang et al. [1] proposed a simplified analysis approach by combining the two-stage method, which was used to solve the effects of lateral displacement of soil on pile. LeBlanc et al. [8], De Sanctis and Russo [9], and Kitiyodom and Matsumoto [10] have conducted corresponding studies that mainly focused on the behaviors of piles under pure transverse loads. However, loads on pile foundation might occur in inclined or combined forms in actual service. Karthigeyan et al. [11], Chien et al. [12], Lee et al. [13], and Mu et al. [14] have found that pile responses under combined loads differ significantly from those under pure vertical or pure horizontal loads. $\mathrm{Mu}$ et al. [15] studied the responses of a single pile under the combined effect of vertical and transverse loads through a series of experiments and found that vertical loads can increase the horizontal resistance of a single pile. These studies did not consider the soil masses surrounding the pile. Considering actual layering conditions in depth range of pile foundation, Goh et al. [6], Ashour et al. [16], and Yang and Boris [17] evaluated the lateral behaviors of piles with two soil layers. Jing et al. [18] studied the lateral displacement and bending moment of deep mixed pile at different embankment positions by using the slope failure mode and found that the maximum bending moment always occurs in the soft-hard soil interface. These studies considered few soil layers and mainly two soil layers (soft and hard soil layers), which is apparently different from actual engineering. Moreover, they did not consider the relative thickness of the soft and hard soil layers. Hence, further studies should be conducted. The key to studying horizontal resistance of pile foundation is to determine the lateral displacement of the pile. The most accurate method of determining the lateral displacement of pile is through an in situ test or experimental study, as proposed by Chien et al. [12], Guo and Ghee [19], and Reddy and Ayothiraman [20]. However, the method is difficult to apply in actual engineering. The empirical approach and finite element method are widely used. The empirical approach was developed from the accumulation of many engineering projects and is applied to certain cases only. In special situations, the empirical approach might cause large errors. With the improvement of the performance of computers, large finite element software has been applied to analyze engineering problems, which could obtain accurate results. Yang and Boris [17], Hazzar et al. [21], Zhang et al. [22, 23], Souri et al. [24], and Chen and Hsu [25] studied the behaviors of pile under transverse load by using the finite element method. Subsequently, Karthigeyan et al. [11] discussed the effects of axial load on the lateral resistance of pile foundation through a numerical simulation. Zhang and Li [26] studied the bending features of pile under the combined effect of axial load and lateral displacement of piles by using the 3D nonlinear elastoplasticity finite element method. Choi et al. [27] studied the influence of bed rock depth on load-displacement curve, displacement, and bending moment of pile body by using the FLAC3D finite difference analysis program. To combine analysis results and practices, Poulos [2] studied ground displacement caused by excavation by establishing a 2D model and using the FLAC software. Karimm et al. [28] studied the combination of $2 \mathrm{D}$ and $3 \mathrm{D}$ analysis approaches in influences of postconstructed embankment on the original piles.

Currently, few studies focus on multilayer soil mass and negative frictional resistance surrounding piles caused by stacking loads. To further discuss the effects of lateral movement of soil mass on pile under complex terrain conditions, this paper discussed the effects of lateral displacement of soil mass on pile by using finite element numerical simulation and studied the lateral resistances of pile foundation under stacking loads in different construction stages in actual engineering.

\section{Principle of MIDAS/GTS Finite Element Method and Numerical Model}

2.1. Principle of MIDAS/GTS Finite Element Method. In this study, the large commercial finite element software MIDAS (Geotechnical and Tunnel Analysis System) was applied for numerical simulation analysis. MIDAS organically combines the universal finite element analysis core and professional requirements of rock tunnel structure. MIDAS integrates the advantages of existing rock tunnel analysis software and solves the displacement field and stress field of the whole structure well, including displacement distribution, size, positions of stress concentration, area, and scope of plastic region. The operation process mainly includes the definition of attributes, establishment of geometric model, meshing, setting of analysis conditions, analysis, and result examination. Six calculation steps are performed.

(1) Discretization of structure: in the discretization of structure, the calculation object is viewed as a continuum and then divided into finite elements. Next, nodes are set at appointed points of elements. The adjacent elements connect mutually at nodes only. The shape, materials, load, and boundary conditions of the discretized structure are the same as those of the original structure.

(2) Selection of shape function: in accordance with the chosen shape function, the relation formula that expresses node displacement at any point in the formula can be deduced. The matrix form is

$$
\{\omega\}=[N]\{\delta\}^{e},
$$

where $\{\omega\}=\left[\omega_{x}, \omega_{z}\right]^{T}$ is the displacement component array at any point and $\{\delta\}^{e}=\left[\omega_{x i}, \omega_{z i}, \omega_{x j}, \omega_{z j}, \omega_{x m}, \omega_{z m}\right]^{T}$ is the displacement array at element nodes $i, j$, and $m$. The shape function matrix $[N]=\left[\begin{array}{cccccc}N_{i} & 0 & N_{j} & 0 & N_{m} & 0 \\ 0 & N_{i} & 0 & N_{j} & 0 & N_{m}\end{array}\right]$ is the function of the node coordinates. With respect to the triangle element with three nodes, a linear mode can be hypothesized. Therefore, (1) can be rewritten as

$$
\begin{aligned}
\omega_{x}(x, z)= & N_{i}(x, z) \omega_{x i}+N_{j}(x, z) \omega_{x j} \\
& +N_{m}(x, z) \omega_{x m}, \\
\omega_{z}(x, z)= & N_{i}(x, z) \omega_{z i}+N_{j}(x, z) \omega_{z j} \\
& +N_{m}(x, z) \omega_{z m} .
\end{aligned}
$$


(3) Establishment of the relationship between element stress and nodal displacement: the relation formula that expresses element strain by nodal displacement, known as geometric equation, can be deduced from the geometric equation and (1):

$$
\{\varepsilon\}=[B]\{\delta\}^{e},
$$

where $\{\varepsilon\}=\left\{\varepsilon_{x}, \varepsilon_{z}, \gamma_{x z}\right\}^{T}$ is the strain array of any points in elements in the $x$ and $z$ planes. [B] is the strain matrix,

$$
[B]=\left[\begin{array}{cccccc}
\frac{\partial N_{i}}{\partial x} & 0 & \frac{\partial N_{j}}{\partial x} & 0 & \frac{\partial N_{m}}{\partial x} & 0 \\
0 & \frac{\partial N_{i}}{\partial z} & 0 & \frac{\partial N_{j}}{\partial z} & 0 & \frac{\partial N_{m}}{\partial z} \\
\frac{\partial N_{i}}{\partial z} & \frac{\partial N_{i}}{\partial x} & \frac{\partial N_{j}}{\partial z} & \frac{\partial N_{j}}{\partial x} & \frac{\partial N_{m}}{\partial z} & \frac{\partial N_{m}}{\partial x}
\end{array}\right]
$$

The relation formula of element stress can be deduced from the physical equation and (3) and is the physical equation

$$
\{\sigma\}=[D][B]\{\delta\}^{e},
$$

where $\{\sigma\}$ is the stress array at any point in the element, and $[D]$ is the elasticity matrix or the elastoplasticity matrix related to the material properties of the element. For the plane strain elasticity problem, the equation is

$$
[D]=\frac{E(1-\nu)}{(1+\nu)(1-2 v)}=\left[\begin{array}{ccc}
1 & \frac{v}{1-\nu} & 0 \\
\frac{\nu}{1-\nu} & 1 & 0 \\
0 & 0 & \frac{1-2 \nu}{2(1-\nu)}
\end{array}\right],
$$

where $E$ is the deformation modulus and $\nu$ is Poisson's ratio.

(4) Establishment of the relationship between node force and nodal displacement on the element: on the basis of the principle of virtual work, the relation between node force and nodal displacement on element can be expressed as an equilibrium equation of the element:

$$
\{F\}^{e}=[k]^{e}\{\delta\}^{e},
$$

where $\{F\}^{e}$ is the equivalent node force array of element. Each node $(i, j$, and $m$ ) of any element has two component forces along the $X$ and $Z$ directions. Therefore, $\{F\}^{e}=\left[F_{x i}, F_{z i}, F_{x j}, F_{z j}, F_{x m}, F_{z m}\right] .[k]^{e}$ is the element stiffness matrix. $\{F\}^{e}$ and $[k]^{e}$ are

$$
\begin{aligned}
\{F\}^{e} & =\iint[B]^{T}[\sigma] d x d z, \\
\{k\}^{e} & =\iint[B]^{T}[D][B] d x d z .
\end{aligned}
$$

(5) Establishment of the overall equilibrium equation: the overall stiffness matrix of the structure $[K]$ can be obtained by combining the stiffness matrixes of all elements. Meanwhile, the equivalent node force arrays of different elements are combined, forming the overall load array $[R]$. As a result, the equilibrium equation of the whole structure is

$$
[K]\{\delta\}=\{R\} .
$$

(6) The unknown nodal displacement and element stress are solved.

2.2. Constitutive Model of Soil Mass. When defining material attributes, the selection of a constitutive model of soil mass is crucial to the results. Currently, common yield criteria in the geotechnical engineering world include Tresca yield criterion, von Mises yield criterion, Drucker-Prager yield criterion, Mohr-Coulomb yield criterion, and double-shear stress yield criterion. All these yield criteria have certain adaptive norms. The Mohr-Coulomb yield criterion model can reflect the strength difference effect (S-D effect) of soil mass with different levels of compressive strength and sensitivity to hydrostatic pressure. The yield has the following three expressions:

The Mohr-Coulomb yield criterion is expressed as

$$
\tau_{n}=\sigma_{n} \operatorname{tg} \varphi+c .
$$

Yield condition is expressed by principle stress:

$$
\sigma_{1}-\sigma_{3}=\left(\sigma_{1}+\sigma_{3}\right) \sin \varphi+2 c \cos \varphi .
$$

If expressed by invariants,

$$
\begin{aligned}
f= & -\frac{1}{3} I_{1} \sin \varphi+\sqrt{J_{2}} \sin \left(\theta_{\sigma}+\frac{\pi}{3}\right) \\
& -\frac{1}{\sqrt{3}} \sqrt{J_{2}} \cos \left(\theta_{\sigma}+\frac{\pi}{3}\right) \sin \varphi-c \cos \varphi=0, \\
I_{1}= & \sigma_{11}+\sigma_{22}+\sigma_{33}, \\
J_{2}= & -S_{11} S_{22}-S_{22} S_{33}-S_{33} S_{11}+S_{12}{ }^{2}+S_{23}{ }^{2}+S_{31}{ }^{2},
\end{aligned}
$$

where $\tau_{n}$ is the ultimate shear stress, $\sigma_{n}$ is the ultimate positive stress, $\varphi$ is the internal frictional angle of material, $c$ is the cohesion of materials, $\sigma_{1}, \sigma_{3}$ are the principal stress, $I_{1}$ is the first principal invariant of the tensor of stress, $J_{2}$ is the second invariant of the deviation tensor of stress, and $\theta_{\sigma}$ is the local angle that ranges between $(-\pi / 6, \pi / 6)$.

Rock material is a granular material and mainly bears load through frictions of particles. The displacement and failure of rock materials are influenced by friction. Particles overcome frictions and cause relative slippage failure as a result of the combined effects of shear stress and vertical stress. Therefore, the Mohr-Coulomb yield criterion is relatively applicable to rock mass. In the principal stress space, the Mohr-Coulomb yield surface considering influences of hydrostatic pressure is an irregular pyramid surface with a hexagonal section and is projected into a hexagon with unequal angles in the $\pi$ plane (Figure 1). Compared with the other criteria, the Mohr-Coulomb yield criterion model has better comparability and requires relatively less parameter information. The needed cohesion $(c)$ and internal friction angle $(\varphi)$ can be tested by conducting a conventional test, which has important roles in engineering practice and has been widely applied. 
TABLE 1: Information of soil.

\begin{tabular}{lcccccc}
\hline Name & Thickness of soil & $\begin{array}{c}\text { Deformation } \\
\text { modulus } \\
E(\mathrm{MPa})\end{array}$ & Poisson's ratio $v$ & $\begin{array}{c}\text { Unit weight } \\
\gamma\left(\mathrm{kN} / \mathrm{m}^{3}\right)\end{array}$ & $\begin{array}{c}\text { Cohesive } \\
c(\mathrm{kPa})\end{array}$ & $\begin{array}{c}\text { Internal friction } \\
\text { angle } \varphi\end{array}$ \\
\hline Filling & $H_{1}=5 \mathrm{~m}$ & 10 & 0.35 & 18 & 15 & 15 \\
Mucky soil & $H_{2}=5 \mathrm{~m}$ & 9 & 0.43 & 16.4 & 18 & 35 \\
Clay & $H_{3}=10 \mathrm{~m}$ & 60 & 0.25 & 25 & 25 \\
Pile & $h=14 \mathrm{~m}$ & 40000 & 0.2 & 25 & \\
\hline
\end{tabular}

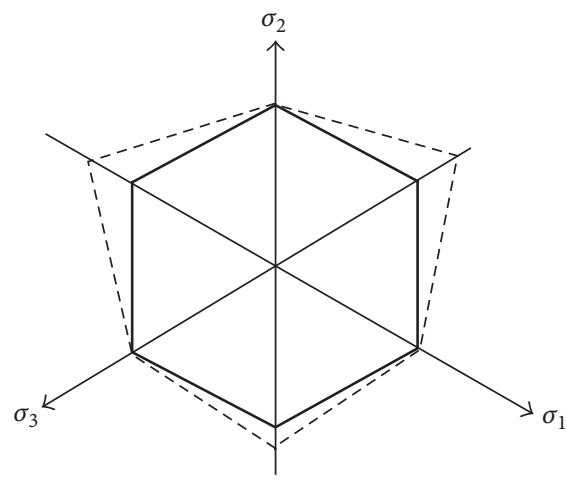

FIGURE 1: Mohr-Coulomb yield surface.

2.3. Numerical Model. The finite element model is shown in Figure 2. $H_{1}$ is filling, $H_{2}$ is soft soil, and $H_{3}$ is clay. Pile foundation selects the linear elastic model and uses beam elements. In order to consider the interaction of pile and soil, the key of modeling is to ensure that the element node of the pile is coincident with the element node of soil, and the mesh size of the soil and the pile is $1 \mathrm{~m}$. Poisson's ratio, unit weight of soil, and elasticity modulus are set to $0.2,25 \mathrm{kN} / \mathrm{m}^{3}$, and $40 \mathrm{GPa}$, respectively. To study the effect of pile size on lateral displacement, pile diameter is set to $0.8,1.0$, and $1.2 \mathrm{~m}$. The mature Mohr-Coulomb model is chosen for rock and soil masses. Solid elements are used. Initial deformation modulus, Poisson's ratio, cohesion, and specific parameters are listed in Table 1.

\section{Parameter Analysis and Discussions}

3.1. Stacking Loads. Vertical and lateral ( $x$-axis direction) displacements cloud charts of soil mass under $100 \mathrm{kPa}$ stacking load are shown in Figure 3. Figure 3(a) shows that, under stacking loads, a $18 \mathrm{~mm}$ downward displacement is generated on the soil surface. However, soil displacement that surrounds pile foundation is relatively smaller than that of surrounding areas due to pile-soil friction. Figure 3(b) shows that soil mass generates displacement toward two sides by centering at the stacking load, whereas the lateral displacement mainly occurs in the second soft soil layer. Figure 4 shows that the lateral displacement of pile increases with the increase in stacking load, and the maximum displacement is at the pile top. The maximum lateral displacement is $6.14 \mathrm{~mm}$ when the stacking load is $100 \mathrm{kPa}$ and increases to $5.55 \mathrm{~cm}$ when the stacking load is $300 \mathrm{kPa}$, showing an order of growth magnitude. By comparing with the results of other factors, we can find that stacking load is mostly important to the lateral displacement of pile. Figure 5 shows that, with the increase in stacking load, lateral displacement caused by the lateral displacement of soil mass basically achieves a linear growth and reaches the maximum at the top layer. The growth rate of lateral displacement increases continuously.

3.2. Deformation Modulus of the Surface Soil $\left(E_{1}\right)$. As is shown in Figures 6-7, we can find that, with the increase in the deformation modulus of surface soil, the lateral displacements of pile body and at pile top decline gradually, which reflects that the elasticity modulus of surface soil at the pile top is positively related to the lateral restraint of soil mass to the pile. In Figure 6, the maximum lateral displacement of the pile body is $6.14 \mathrm{~mm}$ when the deformation modulus of soil mass is $10 \mathrm{MPa}$. When the deformation modulus increases to $30 \mathrm{MPa}$, the maximum displacement is decreased by $50 \%$ to $2.67 \mathrm{~mm}$. A comparison among the calculated results in Section 3.1 shows that the deformation modulus of surface soil mass is not as important as stacking loads at the pile side. Figure 7 shows that no evident linear relationship is found between the displacement at the pile top and the deformation modulus of the surface soil. Moreover, the increase of the constraint effect decreases with the increase of the surface soil's deformation modulus.

3.3. Pile Diameter. The lateral displacement distribution cloud chart of the pile body under different pile diameters is shown in Figure 8. Combining the calculated results in Figure 9 shows that the lateral displacements of the pile body and the pile top decrease gradually with the increase in pile diameter. However, the reduction degree varies. When the pile diameter increases from $0.8 \mathrm{~m}$ to $1.0 \mathrm{~m}$, the lateral displacements of the pile body and the pile top change slightly. The lateral displacements of the pile body and the pile top decrease from $6.62 \mathrm{~mm}$ to $6.14 \mathrm{~mm}$ only. However, the maximum lateral displacement at the pile top dropped sharply to $3.41 \mathrm{~mm}$ when the pile diameter increased to $1.2 \mathrm{~m}$, thus apparently showing a nonlinear relationship. The linear relationship is developed gradually at different types of soil interface (Figure 10), which could be interpreted from two aspects. On the one hand, the dead load of the pile body increases nonlinearly with the increase in pile diameter, which is beneficial to the increase in the lateral resistance of the pile body. On the other hand, increased pile diameter expands the pile-soil contact area (linear relationship between pile-soil contact area and pile diameter). As a result 


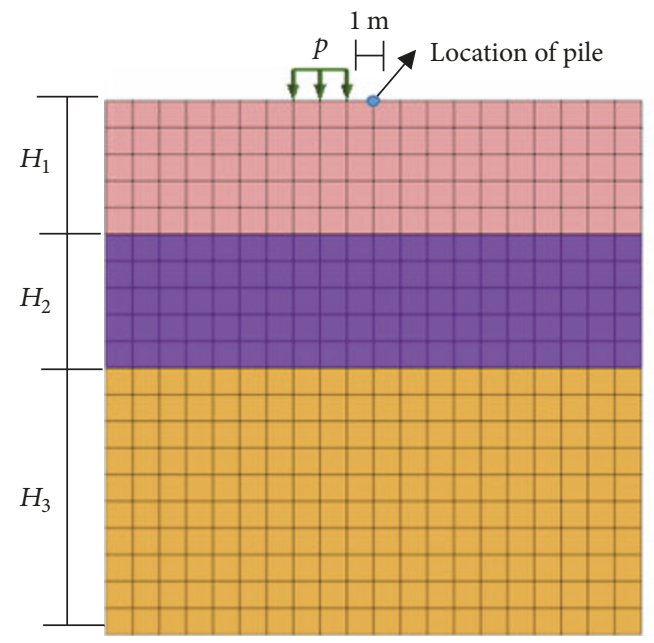

(a) Profile of the soil mode

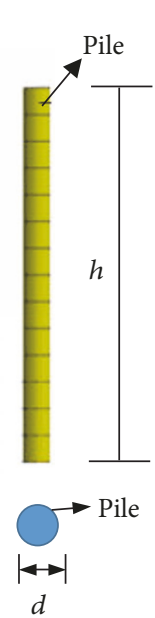

(a)

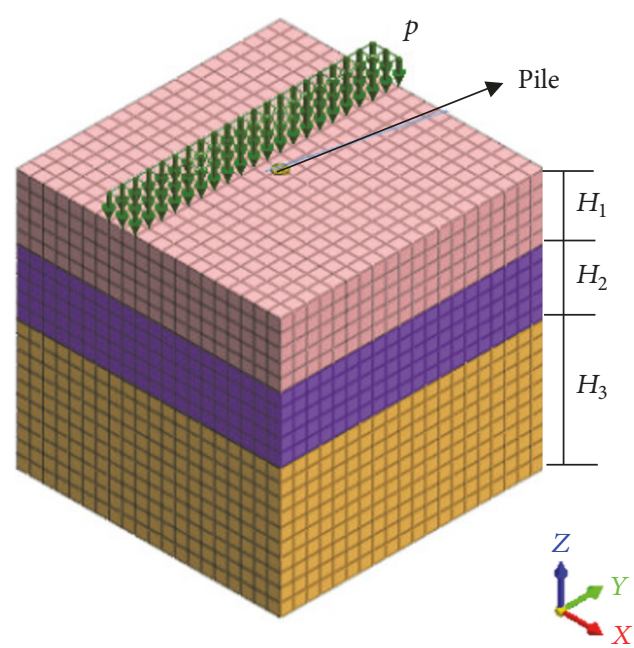

(b) Three-dimensional model of soil

FIgURE 2: Numerical model of pile and soil.

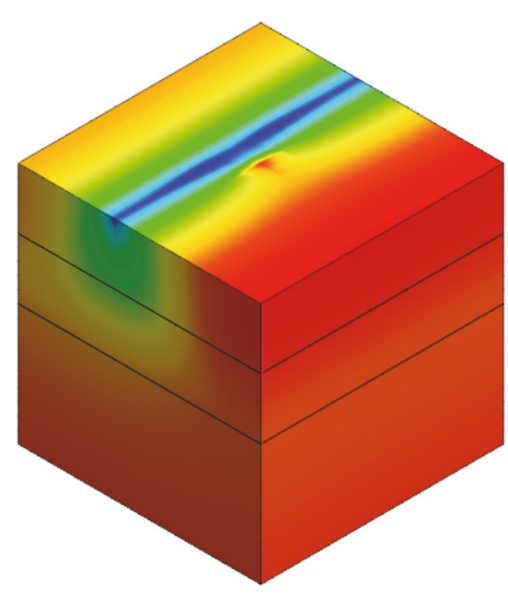

Displacement $T Z, \mathrm{~m}$

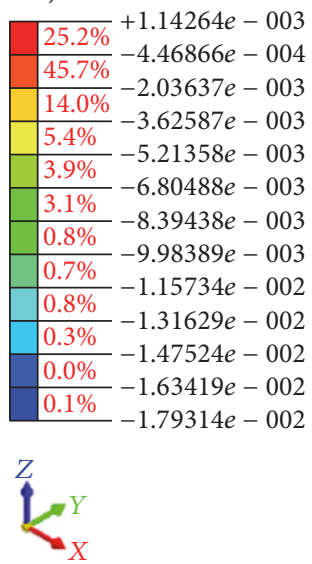

(a) Soil displacement ( $Z$ direction)
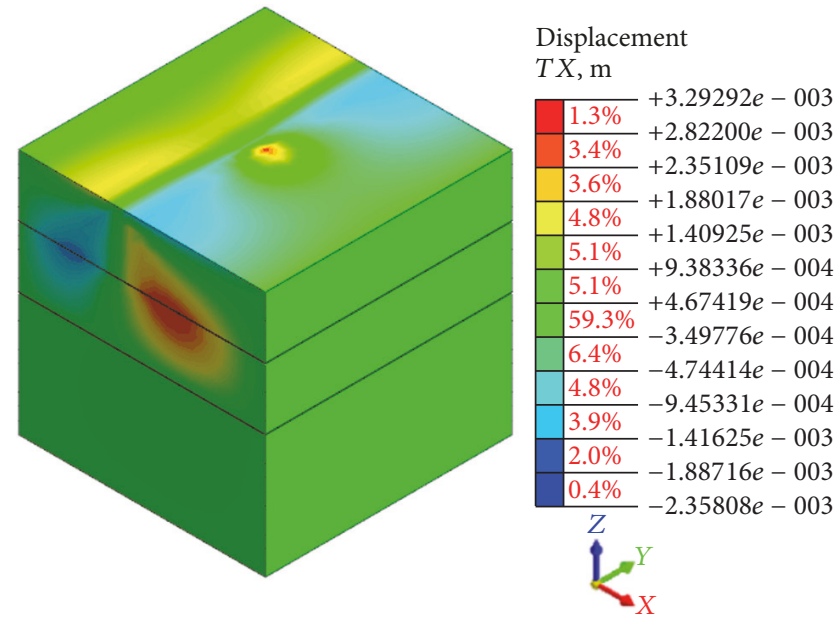

(b) Soil displacement ( $X$ direction)

FIgURE 3: Soil displacement under $100 \mathrm{kPa}$ of stacking loads.

of the frictional force between pile body and soil mass, the lateral displacement of soil mass will cause lateral stress on the pile body and thereby cause lateral displacement of the pile body. The final variation law of lateral displacement of pile body is used to determine which between the dead load or lateral friction of piles takes the dominant role. The dead load takes the dominant role in this case.

3.4. Thickness of Soft Soil. To discuss the effects of relative thickness of soft soil, the deformation modulus of surface soil in the model is determined to be twice the deformation modulus of soft soil. Figures 11 and 12 show that the lateral displacement of the pile body increases with the increase in the relative thickness of soft soil. The lateral displacement of the pile body increases from $3.92 \mathrm{~mm}$ to $6.63 \mathrm{~mm}$ as the soft soil thickness increases from $5 \mathrm{~m}$ to $10 \mathrm{~m}$ (two soil layers).
Figure 12 shows an apparent linear relationship between the pile displacement and the relative thickness of soft soil. Effects of relative thickness of soft soil on the lateral displacement of pile are basically consistent with the deformation modulus of surface soil in Section 3.2. When the deformation modulus of the soil mass that surrounds the pile top decreases, the lateral constraint to the pile top is weakened, thereby increasing pile displacement under lateral displacement or forces. On the basis of the computational analysis, given the thick soft soil layer, the replacement thickness can be determined according to the displacement limit and properties of filling soils, which avoids unnecessary excessive filling.

3.5. Effects of $E_{1} / E_{2}$. The effects of deformation modulus ratio of the adjacent hard soft layer and soft soil layer $\left(E_{1} / E_{2}\right)$ on the lateral displacement of the pile body are 


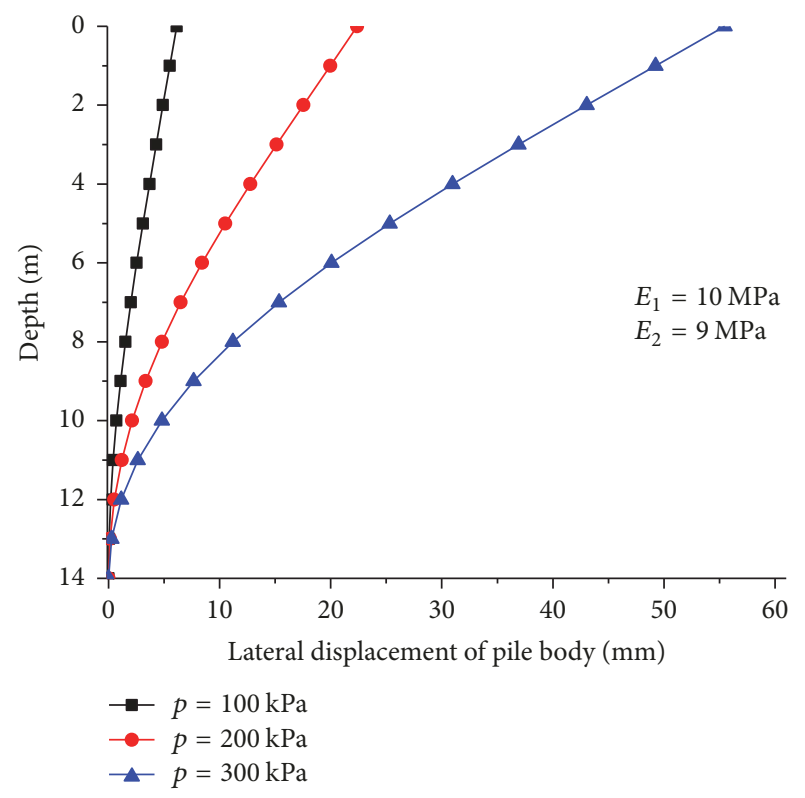

FIGURE 4: Relationship between lateral displacement of pile and stacking loads.

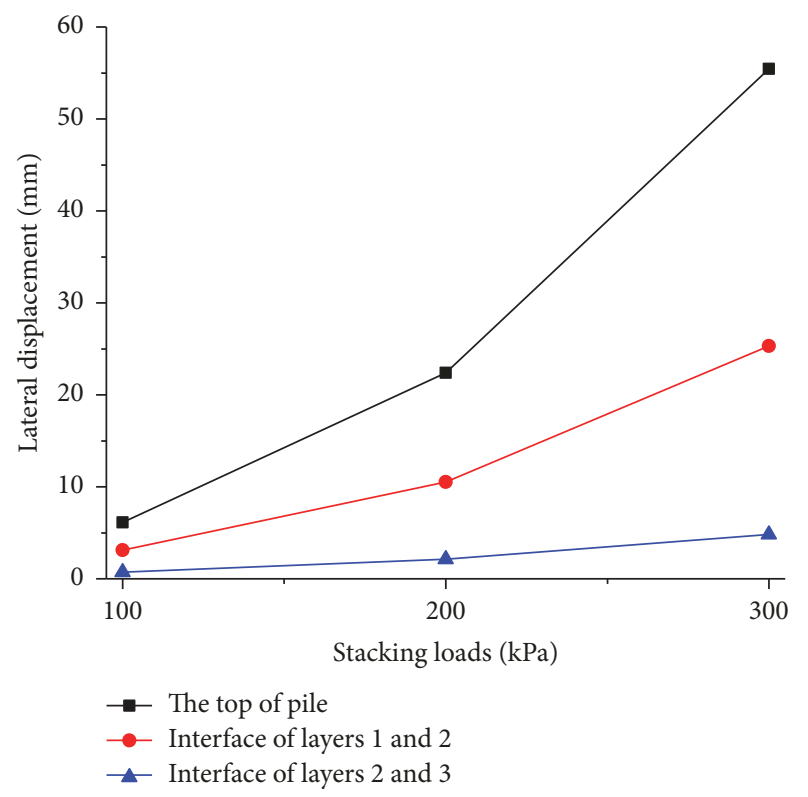

FIGURE 5: Relationship between lateral displacement and stacking loads at different positions.

shown in Figures 13 and 14 . With the increase of $E_{1} / E_{2}$, the maximum lateral displacement of the pile body decreases gradually. However, the reduction amplitude varies. When $E_{1} / E_{2}$ increases from 1 to 2 , the total reduction amplitude is $40 \%$. When $E_{1} / E_{2}$ increases to 3 , the total reduction amplitude is $56 \%$, and the relative reduction amplitude is only $16 \%$, which indicates that increasing $E_{1} / E_{2}$ can prevent and solve the lateral displacement of the pile body effectively. However, $E_{1} / E_{2}$ (2 in this case) can have a significant effect in a certain range. The effect will become insignificant when

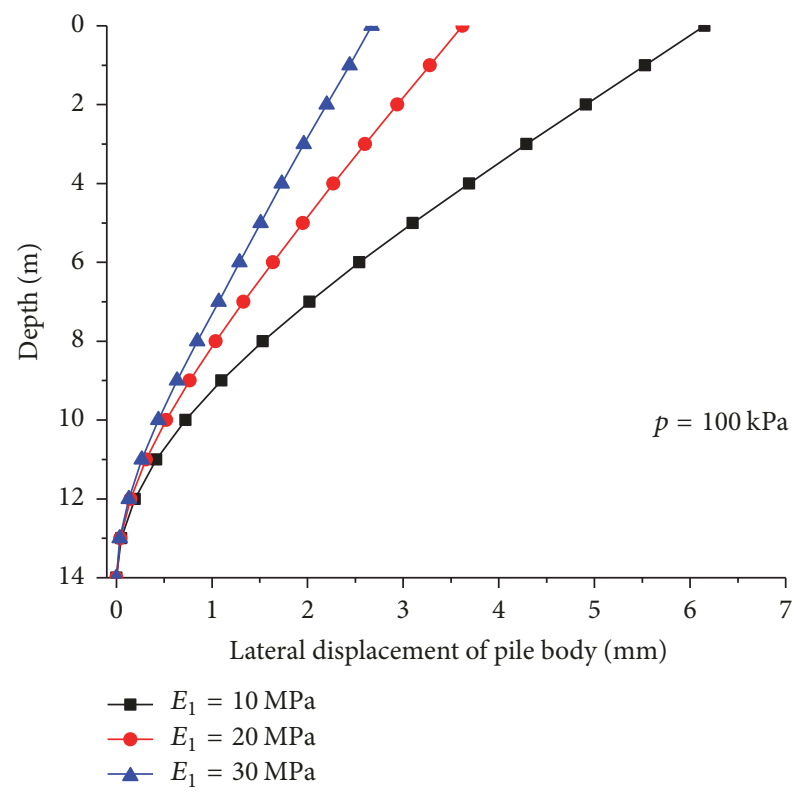

FIgURE 6: Relationship between lateral displacement of pile and $E_{1}$.

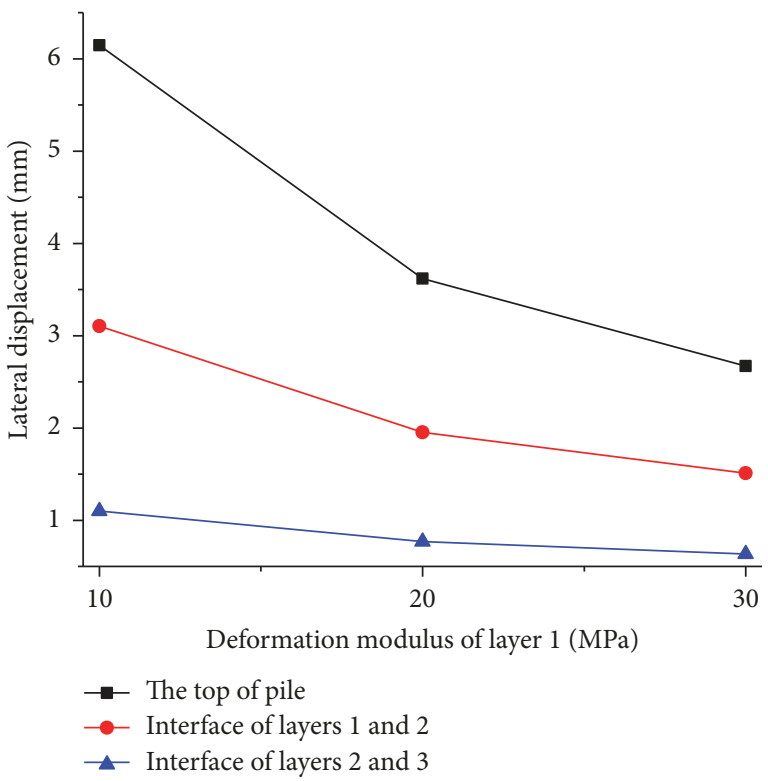

FIGURE 7: Relationship between lateral displacement and $E_{1}$ at different positions.

the value is exceeded. In specific engineering, finite element software can be used to simulate the lateral displacements of pile body under different $E_{1} / E_{2}$, when foundation processing of surface soil mass and increasing deformation modulus are needed, thus enabling the appropriate foundation processing to be determined and the lateral resistance demands of the pile body to be met.

3.6. Coupling Effect of Stacking Load and Axial Force at Pile Top. On the basis of Section 3.1, an axial load of $7000 \mathrm{kN}$ is applied on the top of the pile. The result is shown in Figures 15 


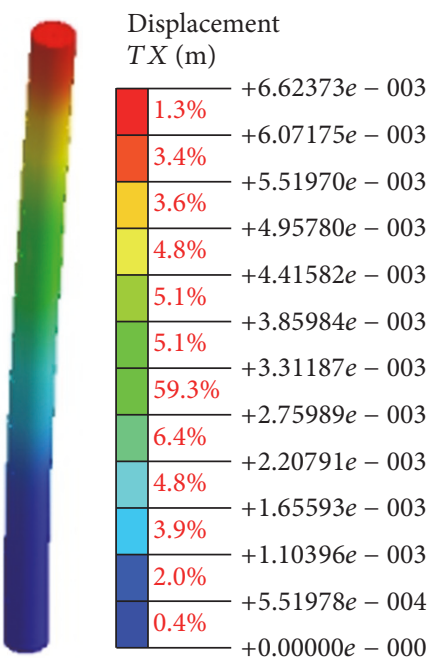

(a) $r=0.8 \mathrm{~m}$

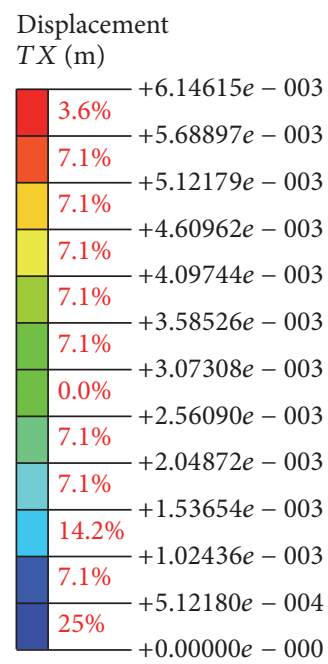

(b) $r=1.0 \mathrm{~m}$

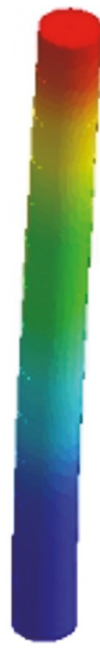

Displacement

$T X(\mathrm{~m})$

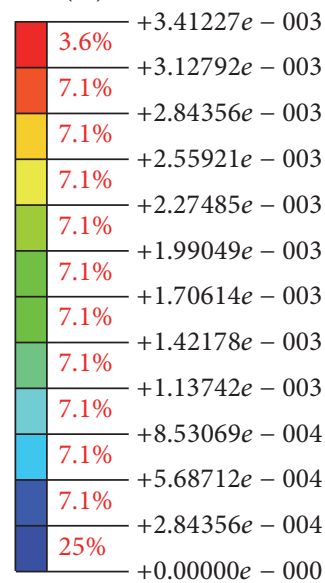

(c) $r=1.2 \mathrm{~m}$

FIgURE 8: The lateral displacement distribution cloud chart of pile body under different pile diameters.

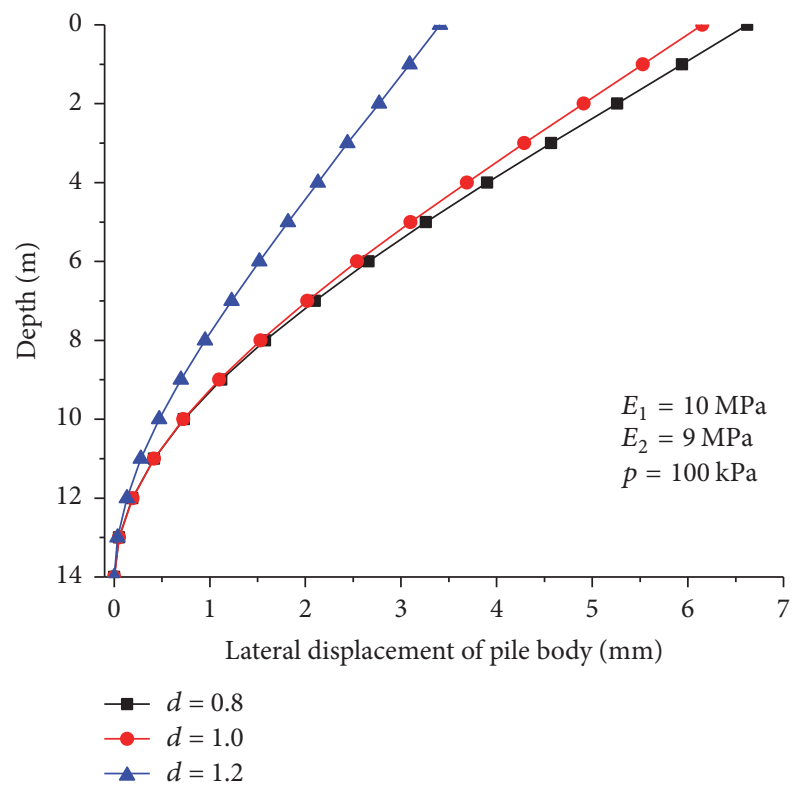

FIGURE 9: Relationship between lateral displacement of pile and pile diameters.

and 16. The lateral displacements of the pile body decrease by $58.8 \%, 57.5 \%$, and $44.9 \%$ respectively, compared to Figure 4. This result indicates that the load at the pile top can reduce the lateral displacement of the pile body significantly because applying axial force at the pile top is equivalent to applying one constraint. Therefore, the free displacement at the pile top is transformed into constrained displacement and limits displacement at the pile top to some extent.

\section{Case Study}

In this section, the lateral displacement of the pile body and the negative frictional resistance of soft soil caused by

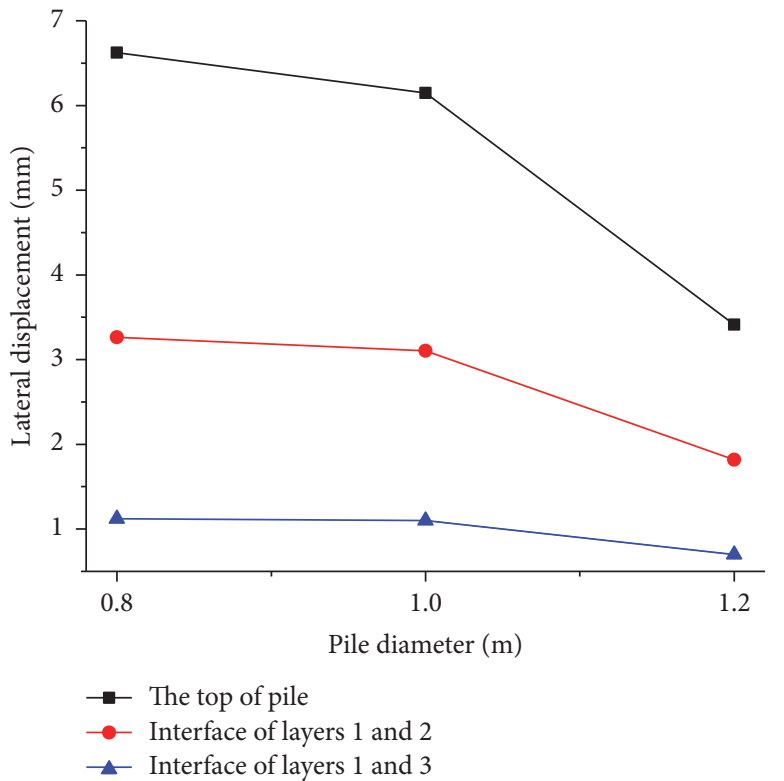

FIGURE 10: Relationship between lateral displacement and pile diameters at different positions.

stacking loads under different working conditions in different construction stages are discussed by combining a real engineering case. The engineering case is a newly constructed embankment with a height of approximately 6-7 $\mathrm{m}$ and runs through an existing bridge project. To avoid adverse impacts of the new embankment on the running safety of the original bridge structure, the embankment body applied a U-typereinforced concrete integrated section, which runs through the whole section in a span of one bridge. To eliminate the compressive displacement of the foundation soil layer by the upper embankment load, the pile foundation was processed by using a small single-tube high-pressure jet 
TABLE 2: Information of soil and pile.

\begin{tabular}{|c|c|c|c|c|c|c|c|}
\hline & Name & $\begin{array}{l}\text { Thickness of soil } \\
\text { (m) }\end{array}$ & $\begin{array}{c}\text { Deformation } \\
\text { modulus } \\
E(\mathrm{MPa})\end{array}$ & Poisson's ratio $v$ & $\begin{array}{l}\text { Unit weight } \\
\gamma\left(\mathrm{kN} / \mathrm{m}^{3}\right)\end{array}$ & $\begin{array}{l}\text { Cohesive } \\
c(\mathrm{kPa})\end{array}$ & $\begin{array}{l}\text { Internal friction } \\
\text { angle } \varphi\end{array}$ \\
\hline (1) & Filling & $0-2$ & 10 & 0.35 & 18 & 15 & 15 \\
\hline$(2)$ & Silty clay & $0.4-3.9$ & 18 & 0.38 & 19.1 & 25 & 14.5 \\
\hline (3) & Coarse sand & $0.5-4$ & 20 & 0.25 & 18 & 0 & 25 \\
\hline$(4)$ & Sand and gravel & $4-6$ & 21 & 0.28 & 21 & 0 & 35 \\
\hline (5) & Sludge & $4.5-5.0$ & 9.25 & 0.43 & 16.4 & 11 & 1.5 \\
\hline (6) & $\begin{array}{l}\text { Completely } \\
\text { weathered }\end{array}$ & $0.5-8$ & 60 & 0.27 & 18.6 & 90 & 25 \\
\hline (7) & $\begin{array}{c}\text { Intense } \\
\text { weathering }\end{array}$ & 30 & 200 & 0.23 & 19.5 & 180 & 35 \\
\hline$(8)$ & $\begin{array}{c}\text { Embankment } \\
\text { backfill }\end{array}$ & $6-7$ & 20 & 0.25 & 18 & 0 & 25 \\
\hline (9) & $\begin{array}{l}\text { Jet-grouted pile } \\
\text { foundation }\end{array}$ & 5 & 400 & 0.3 & 20 & 450 & 30 \\
\hline$(10)$ & Pile/column & $20 / 20$ & 40000 & 0.2 & 25 & & \\
\hline$(11)$ & $\begin{array}{c}\text { U-shaped } \\
\text { concrete tank }\end{array}$ & & 40000 & 0.2 & 25 & & \\
\hline
\end{tabular}

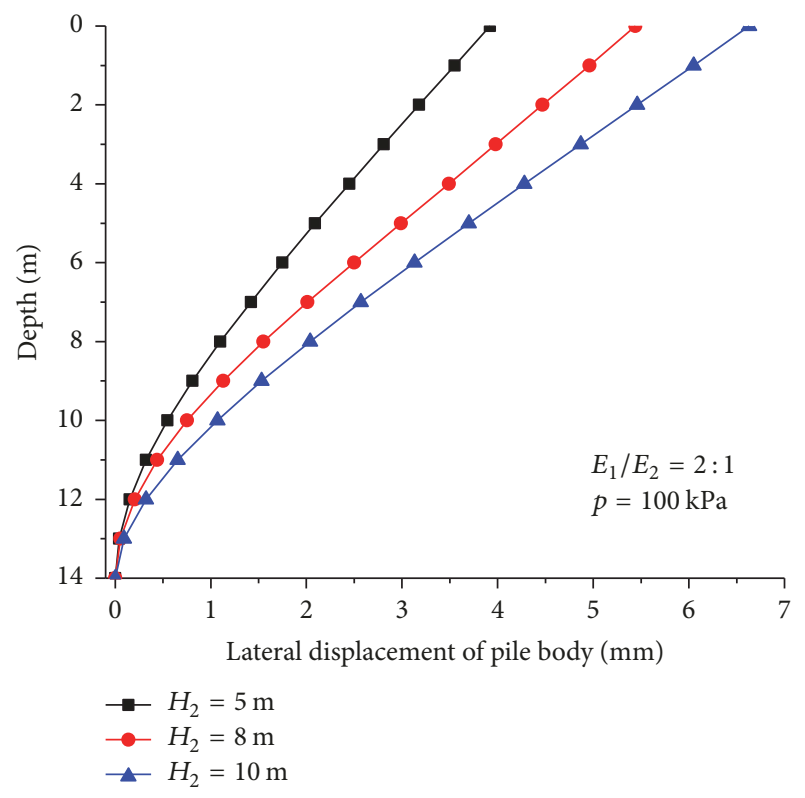

FIGURE 11: Relationship between lateral displacement of pile and relative thickness of soft soil.

grouting pile with simple equipment and small disturbance to the basic soil layer. The geological distribution is shown in Figure 17, the soil parameters are shown in Table 2, and the calculation model is shown in Figure 18. The axial load on the pile foundation is taken as the design bearing capacity of a single pile at $7000 \mathrm{kN}$, and the diameter of the bridge pile is $1.8 \mathrm{~m}$. Numerical simulation analysis mainly considers five construction conditions based on initial rock soil solidification simulation.

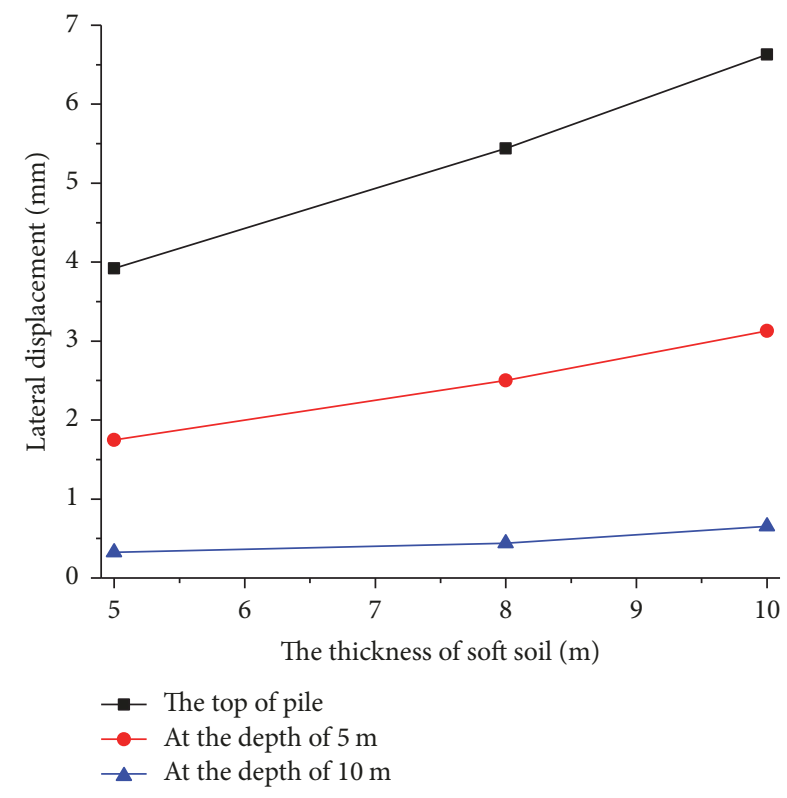

FIGURE 12: Lateral displacement at different positions.

(1) Working Condition 1. Mulanxi bridge pile construction and bridge pile construction are finished.

(2) Working Condition 2. Jet-grouted pile foundation construction is finished.

(3) Working Condition 3. U-shaped concrete pit and surface filling outside the pit are finished.

(4) Working Condition 4. Embankment filling in U-shaped concrete pit is finished. 


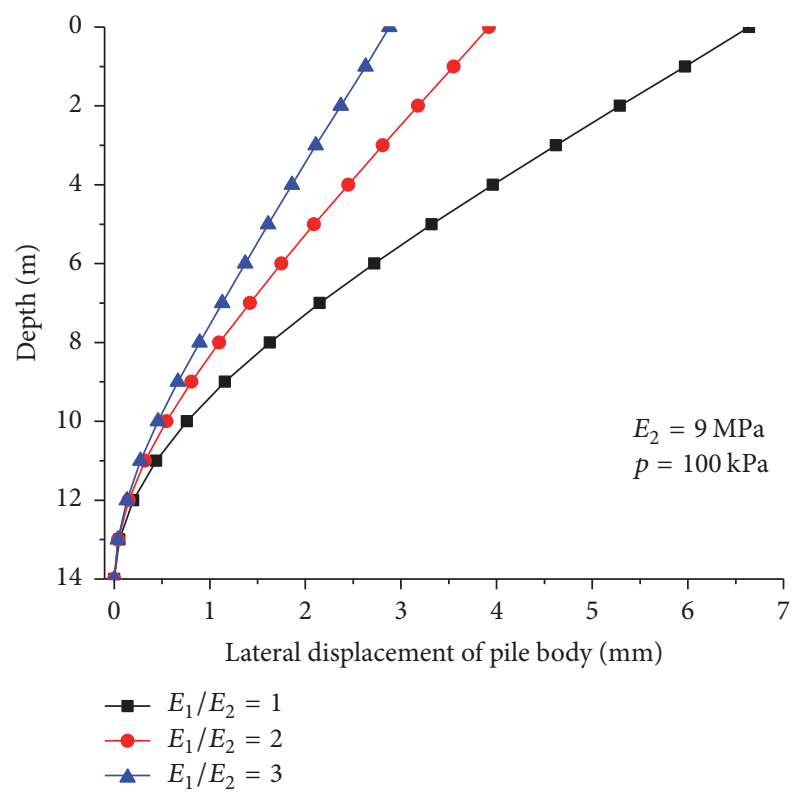

FIGURE 13: Relationship between lateral displacement of pile and $E_{1} / E_{2}$.

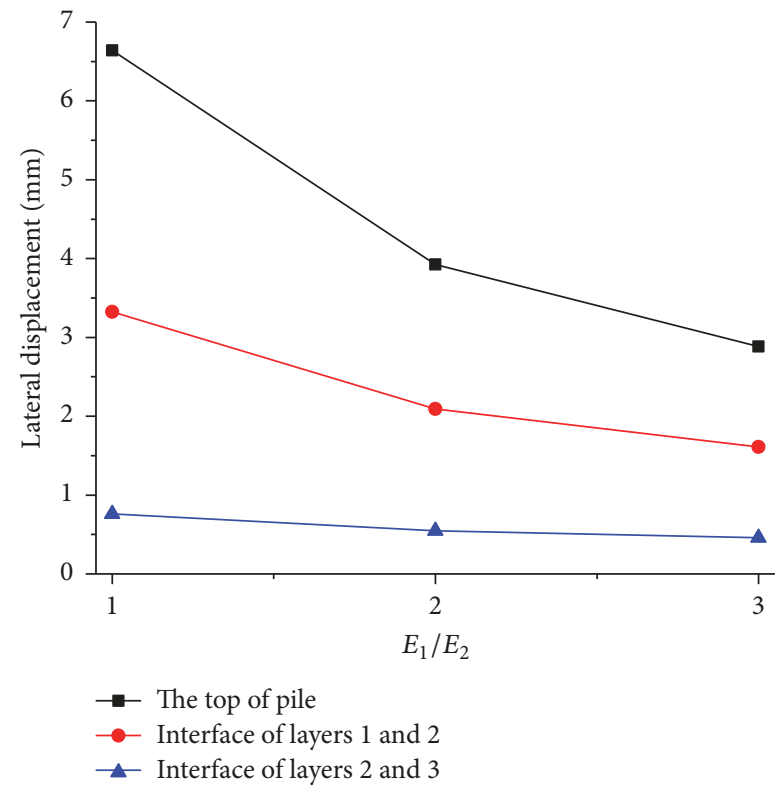

FIGURE 14: Relationship between lateral displacement and $E_{1} / E_{2}$ at different positions.

(5) Working Condition 5. Embankment pavement is run under overloads $(30 \mathrm{kPa})$.

4.1. Lateral Displacement of Bridge Piles and Bridge Columns (x-Axis). The lateral displacements of the bridge pile and pile column under different working conditions are shown in Figure 19. Small lateral displacements, with a size of $3.6 \mathrm{~mm}$, are found at the bridge column top under working conditions 1 and 2. The lateral displacement under working condition 3 increases to some extent and shows displacement expansion

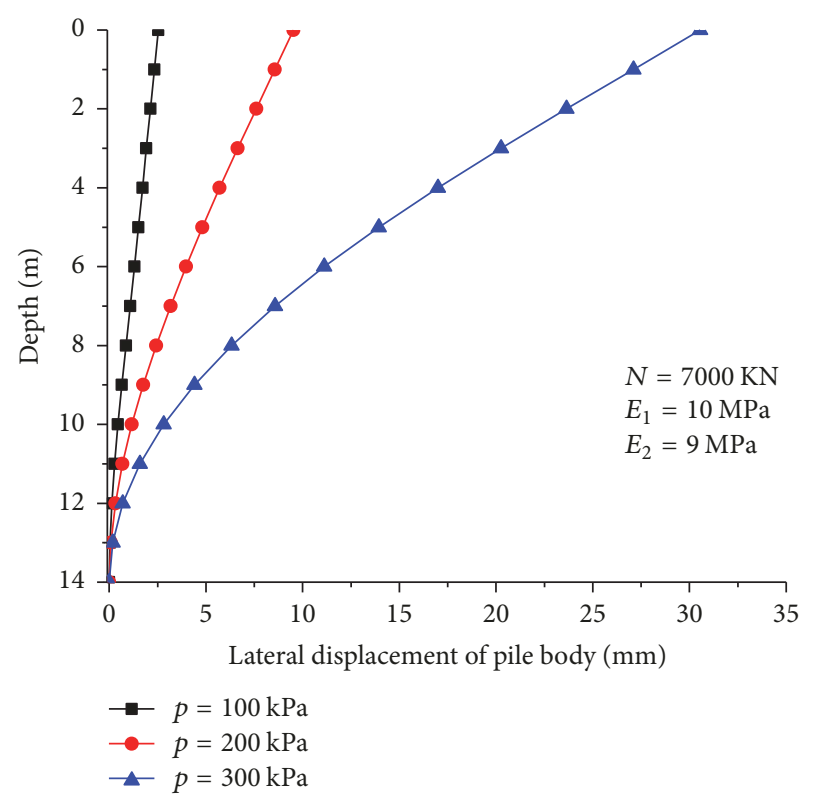

FIGURE 15: Lateral displacement of pile under coupling effect of stacking load and axial force.

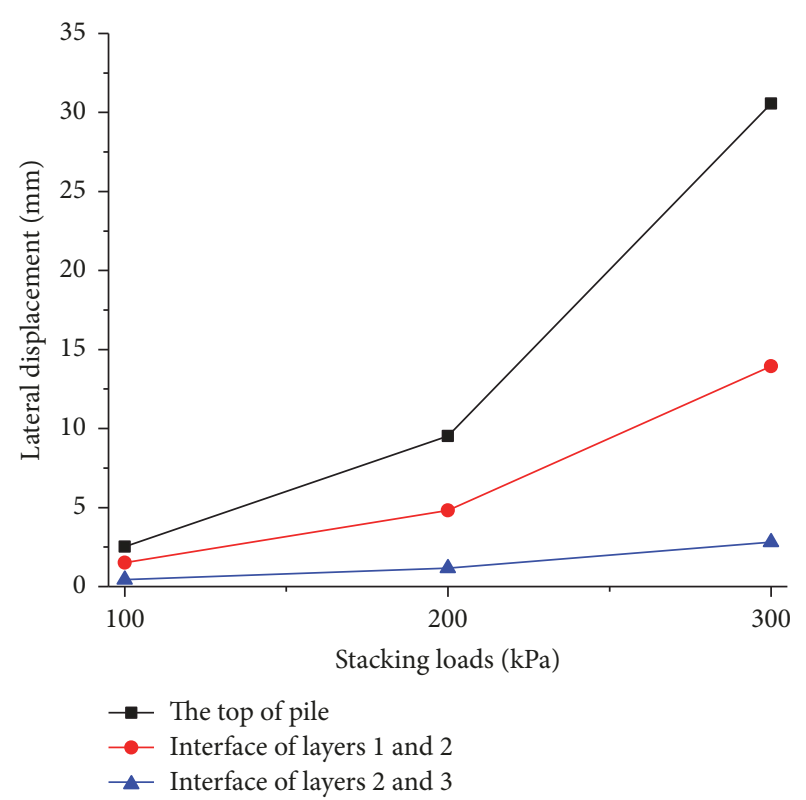

FIGURE 16: Lateral displacement of pile at different positions under coupling effect.

toward two sides. The displacement of the left pile is higher than that of the right pile and has a size of $10 \mathrm{~mm}$. The lateral displacement under working condition 4 increases sharply. The lateral displacement of the left pile reaches $21.3 \mathrm{~mm}$, and the lateral displacement of the right pile is $13.0 \mathrm{~mm}$. The lateral displacement under working condition 5 continues to increase. The lateral displacements of the left and right piles reach 22.9 and $16.9 \mathrm{~mm}$, respectively.

The lateral displacement of the pile along the depth is shown in Figure 20. The lateral displacement under working 


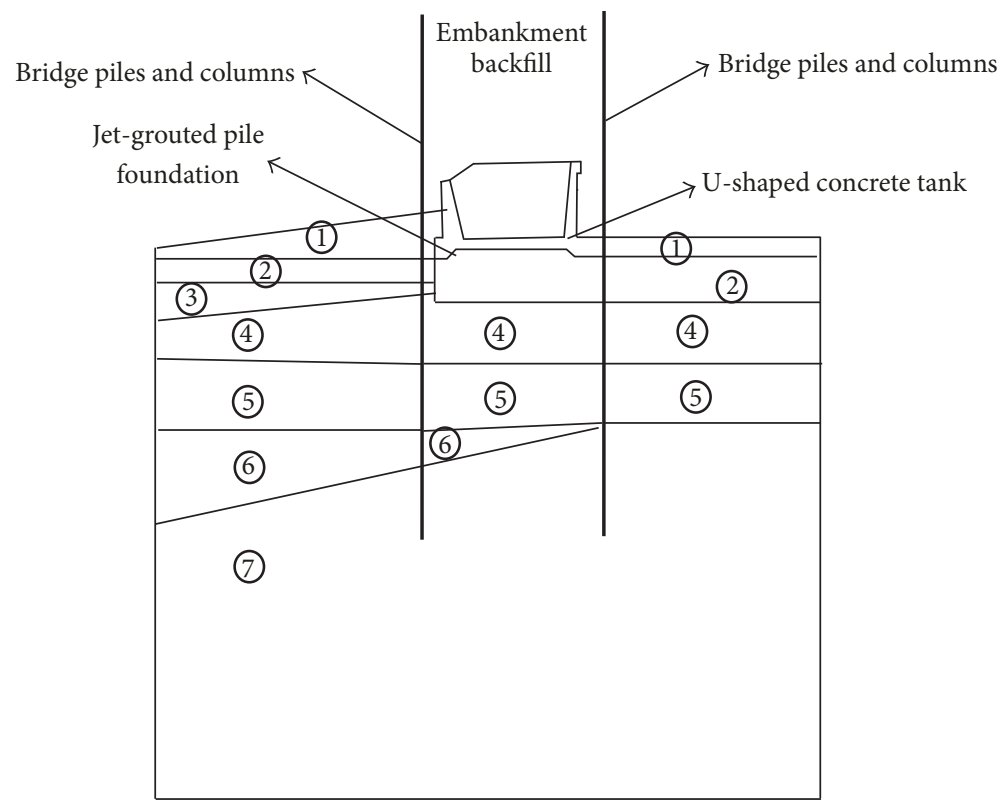

FIGURE 17: Soil layer distribution and calculation model.

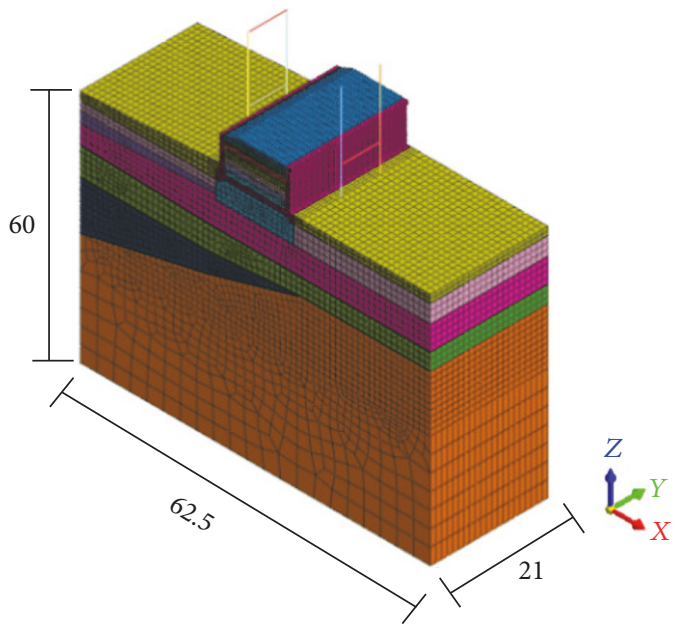

FIGURE 18: Numerical simulation of postconstructed embankment (m).

condition 4 increases dramatically, and the displacement of the right pile is smaller than that of the left pile, mainly because the rock-socketed depth of the left pile is approximately $4 \mathrm{~m}$, whereas the rock-socketed depth of the right pile is approximately $11 \mathrm{~m}$. In the pile region of $28-36 \mathrm{~m}$, the lateral displacement of the right pile is significantly smaller than that of the left pile, thereby resulting in the small inclination of the pile body. Consequently, the lateral displacement at the pile top is relatively small.

The profiles of the lateral displacement under working condition 5 are shown in Figure 21. Soil mass generates lateral compressional displacement in the depth range of approximately $8 \mathrm{~m}$ below the surface close to the bridge piles, thus weakening lateral constraint to the piles. If bridge piles have to be reinforced in the construction process, then doing so can reinforce soil mass in the passive region outside the bridge piles.

\subsection{Lateral Displacement of Bridge Piles and Bridge Columns} ( $y$-Axis). Limited by article length and actual calculation results, only vertical displacements ( $y$-axis direction) of bridge piles and bridge column under working conditions 1 and 5 were introduced in this study (Figure 22). The soil mass did not result in a noticeable lateral displacement in the length range of embankment ( $y$-axis direction) because the postconstructed embankment and pedestrian loads were distributed along the $y$-axis direction. Therefore, loads can slightly influence the longitudinal displacement of the bridge pile and the bridge column. Figure 22 shows that the maximum lateral displacement of the bridge column under working condition 5 is only $0.25 \mathrm{~mm}$, which is also observed in the right bridge column. The longitudinal displacement of the left bridge column is smaller because of the different positions of coupling beams at the left and right sides. One coupling beam at the top of the left side connects two piles and enhances the lateral resistance of $y$-axis displacement significantly.

\subsection{Lateral Displacement of Bridge Piles and Bridge Columns} ( $z$-Axis). To understand the effects of stacking load on the vertical displacement of bridge piles and columns, the vertical displacements of working conditions 1 and 5 of bridge piles and columns were extracted (Figure 23). The extra axial loads with vertical sedimentation under stacking loads are generated and applied onto the pile top, resulting in the maximum axial loads at the pile top. As a result of pile-soil friction, the extra axial loads distribute to the pile end along 


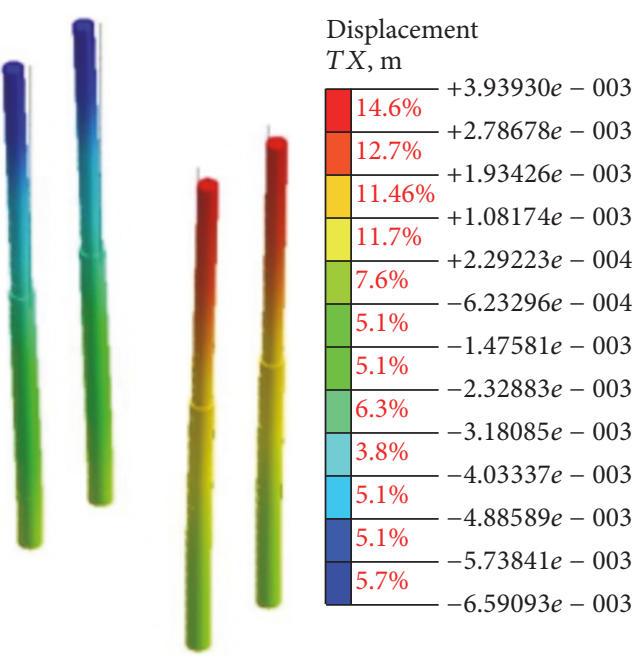

(a) Working condition 2

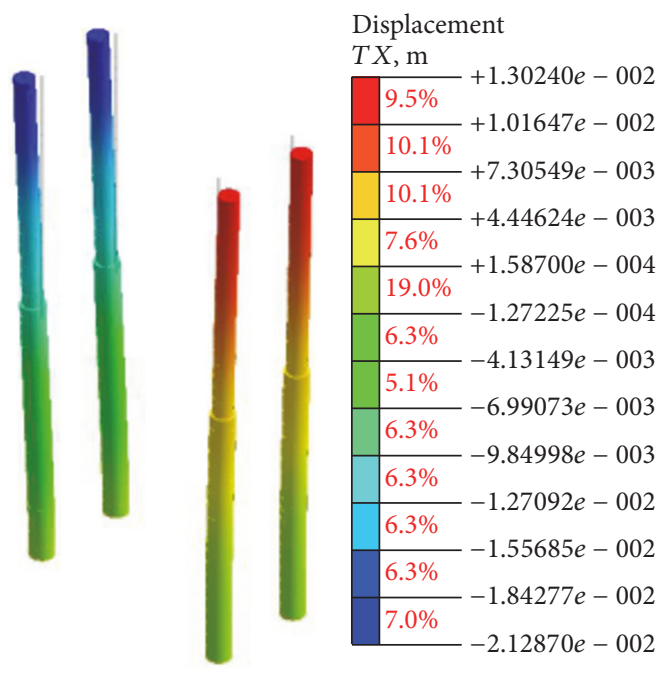

(c) Working condition 4

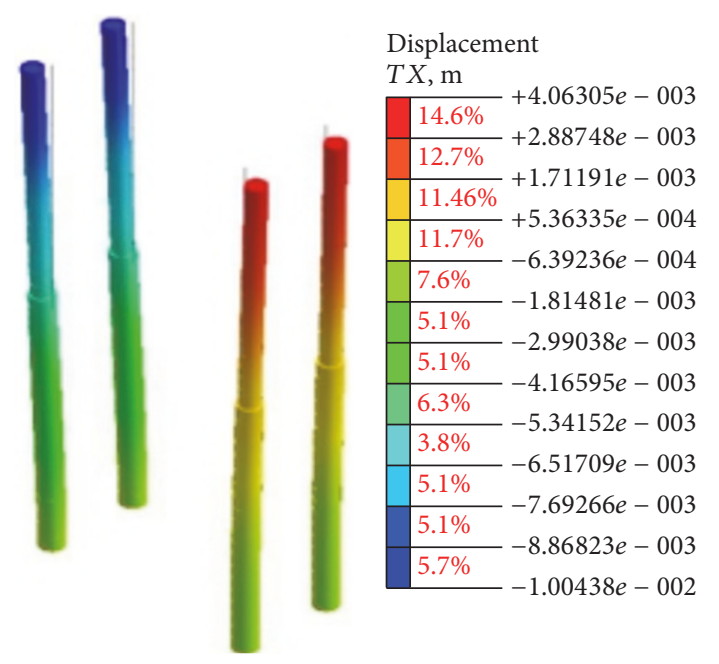

(b) Working condition 3
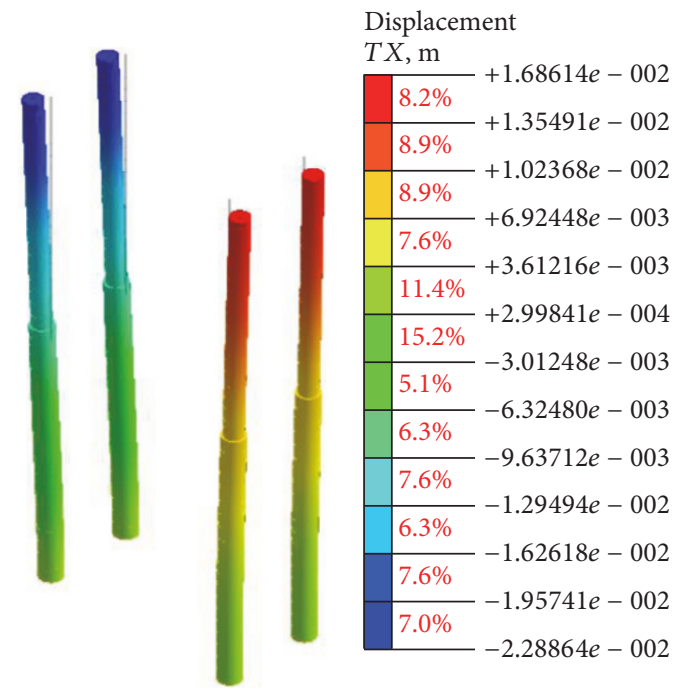

(d) Working condition 5

FIGURE 19: Lateral displacement of bridge piles and columns under different working condition.

the pile top and decrease gradually. The vertical displacement of the bridge pile reaches the maximum at the op according to mechanics knowledge of materials but declines gradually with the increase in depth. These findings are consistent with the cloud chart in Figure 23. The maximum displacements under working conditions 1 and 5 are 3.81 and $4.31 \mathrm{~mm}$, respectively. Compared with the length of the pile column, the vertical displacement of bridge columns is insignificant under most unfavorable construction working conditions of the project, and the effects can be neglected.

4.4. Axial Forces of Bridge Piles and Columns. Variations of axial forces of bridge piles and columns under five working conditions are shown in Figure 24. Spinning pile treatment was performed for foundation construction after bridge pile construction. The axial force of the pile body basically remains the same but increases to some extent along the pile body because the model calculation considers the effects of gravity. The axial force of the bridge piles under working conditions 3,4 , and 5 increases sharply compared with that of working condition 2. However, the axial force of bridge piles under working condition 5 is slightly higher than that of working condition 4 . Figure 24 shows that the axial force of the pile body increases continuously as it proceeds deeply. The slopes of the curve changes of axial forces in working conditions 3, 4, and 5 are smaller than those of the first two working conditions, indicating that considerable dropdown loads are generated along piles. Combining Figures 23(b) and 25, the vertical displacement of the pile body is at a millimeter level, and significant displacement of soil mass is basically at a centimeter level. The vertical sediment of the soil mass surrounding the bridge piles is larger than that of the vertical displacement of the piles, thus creating frictional resistance on the piles downward and generating downward 


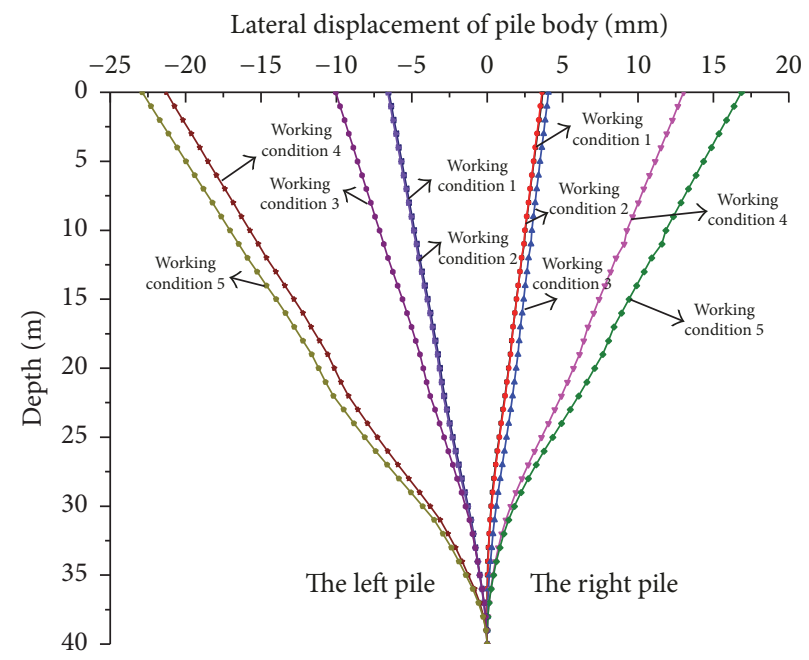

FIGURE 20: Lateral displacement of left and right bridge piles and columns.

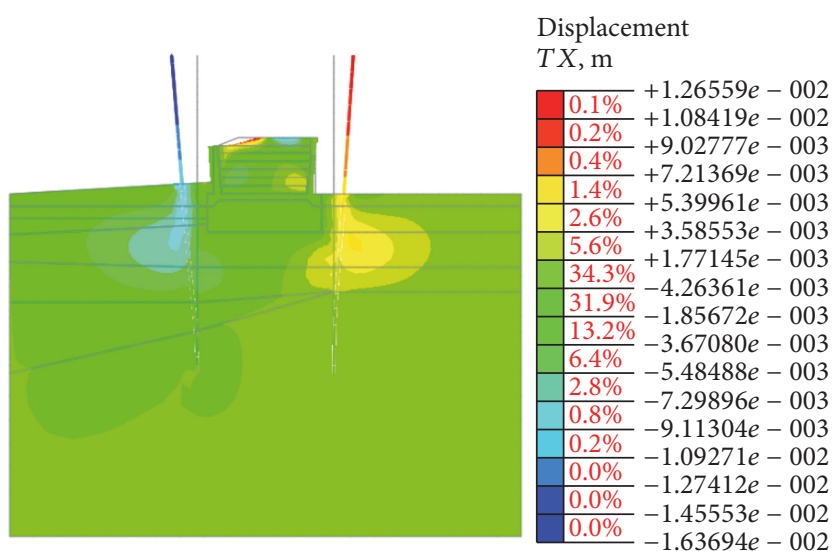

FIGURE 21: Profiles of bridge pile columns and lateral displacement of foundation soil-working condition 5.

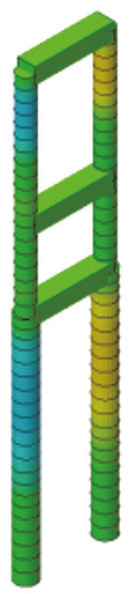

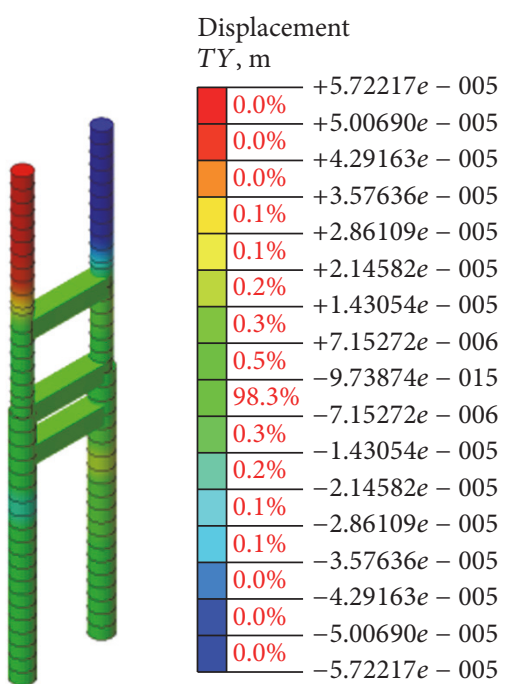

(a) Working condition 1
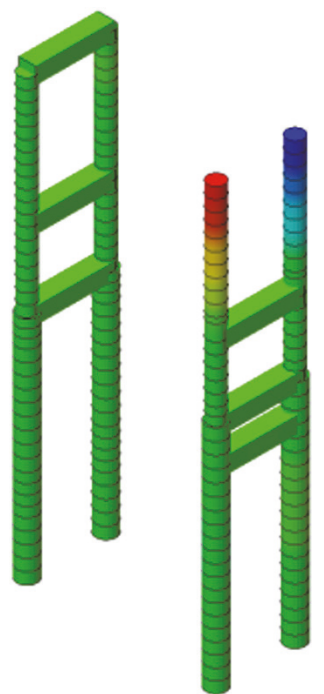

Displacement

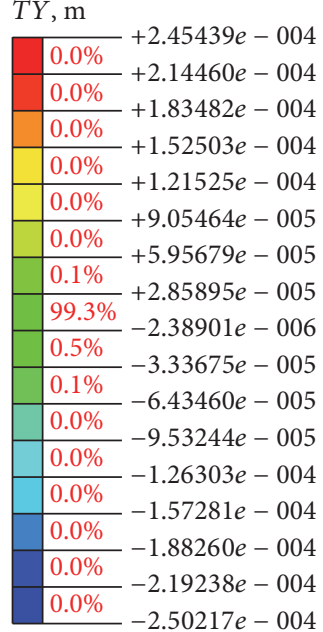

(b) Working condition 5

FIGURE 22: Longitudinal displacement of bridge piles. 


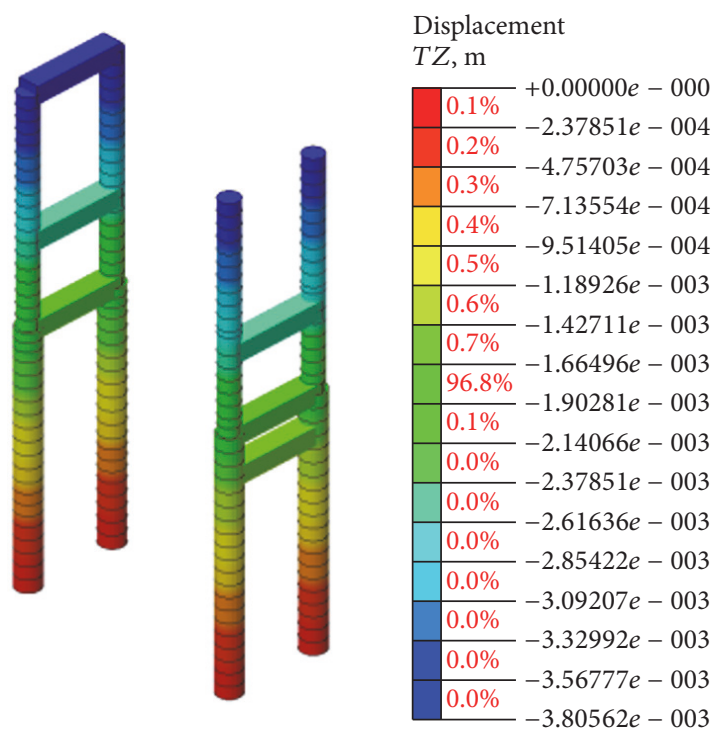

(a) Working condition 1

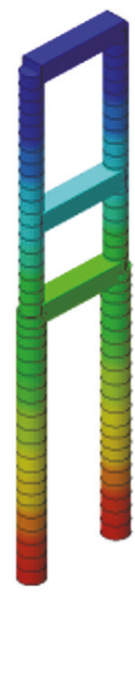

Figure 23: Vertical displacement of bridge piles and columns.

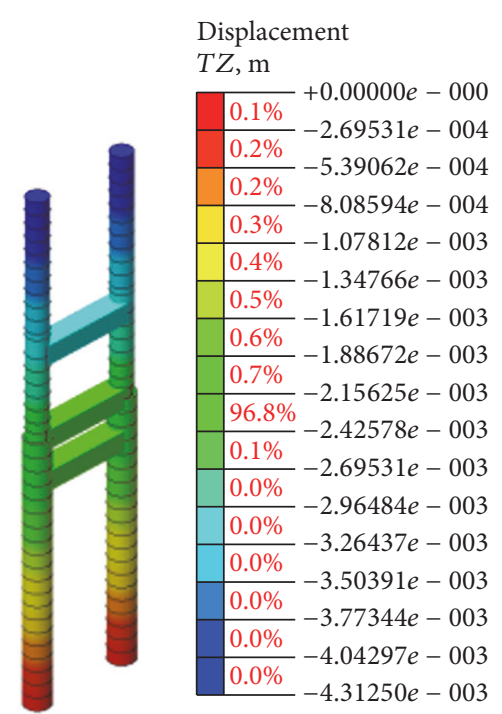

(b) Working condition 5 


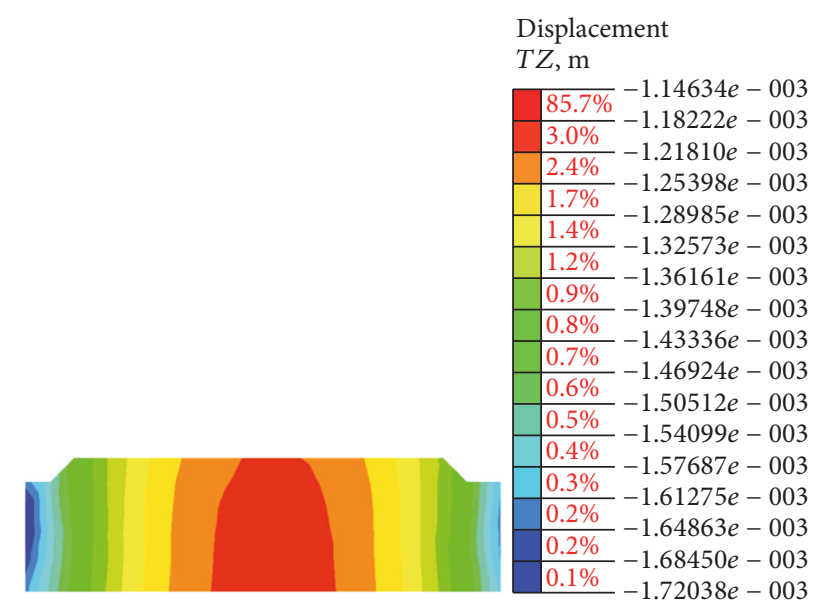

(a) Working condition 2

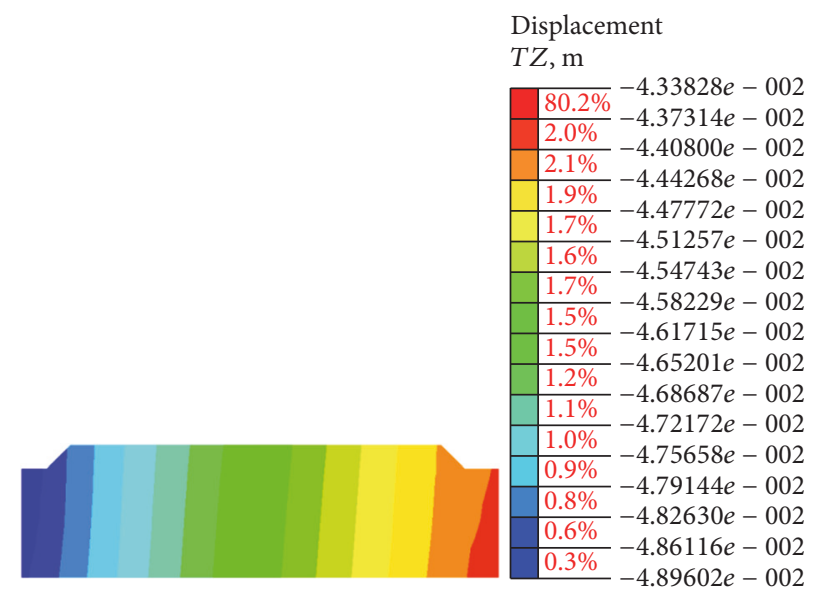

(c) Working condition 4

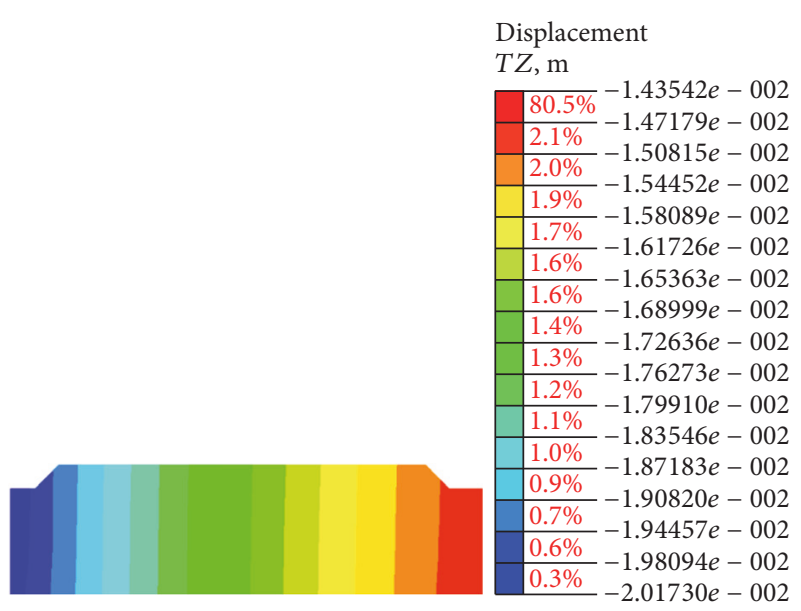

(b) Working condition 3

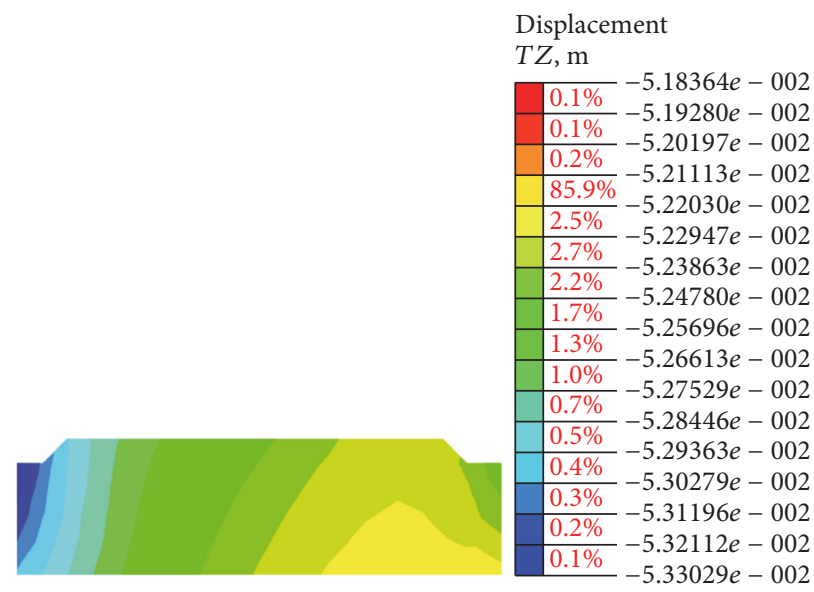

(d) Working condition 5

FIgURE 26: Vertical settlement of foundation after spinning pile processing.

from free displacement. The lateral displacement of piles $(x$ axis direction) causes the soil mass in front of piles to generate active earth pressure and the soil mass behind piles to generate passive earth pressure. Plastic displacement is generated when the earth pressure exceeds the strength of soil mass. The maximum principal plastic strain of soil mass under five working conditions is shown in Figure 27. The lateral displacements of the pile body under working conditions 1 and 2 are relatively small. Moreover, no plastic zones are formed in the foundation soil. The lateral displacement of the pile body increases with the increase of working condition 3 , and the soil mass range in the accessories section surrounding piles develops a plastic zone. The range and depth of the plastic zone increase gradually from working conditions 1 to 5 , which is in agreement with the lateral displacement of the pile body in Figure 19.

To understand the plastic region size of soil mass, the vertical and plane views of the maximum principal plastic strain of soil mass under working condition 5 are shown in Figures 28 and 29. The plastic zone of the left bridge pile covers a $1.5 \mathrm{~m}$ radius away from the bridge pile and a depth of approximately $8 \mathrm{~m}$. The plastic zone of the right bridge pile covers a $1.0 \mathrm{~m}$ radius away from the bridge pile and a depth of approximately $6 \mathrm{~m}$. Similar to that in Section 4.1, the rock-socketed depth of the left pile is smaller than that of the right pile, resulting in different lateral displacements of the right and left piles, as well as different active and passive earth pressures on soil mass in the front and back of the piles. Therefore, the plastic zones of soil mass have different ranges.

On the basis of the above numerical analysis, attention is given to the monitoring of lateral displacement and axial force of bridge columns in actual construction to ensure the safety and stability of the original bridge pile foundation. The construction shall be stopped immediately if the lateral displacement of pile columns is too large, the displacement rate is high, or the displacement exceeds a certain value. The causes of such occurrences shall be analyzed. Considering the analysis results for the lateral displacement of the pile body in Section 3, the following emergency measures can be adopted as necessary:

(1) Piling pressure is applied at the external side of the bridge pile.

(2) Soil mass in a certain range outside the bridge pile is reinforced. 


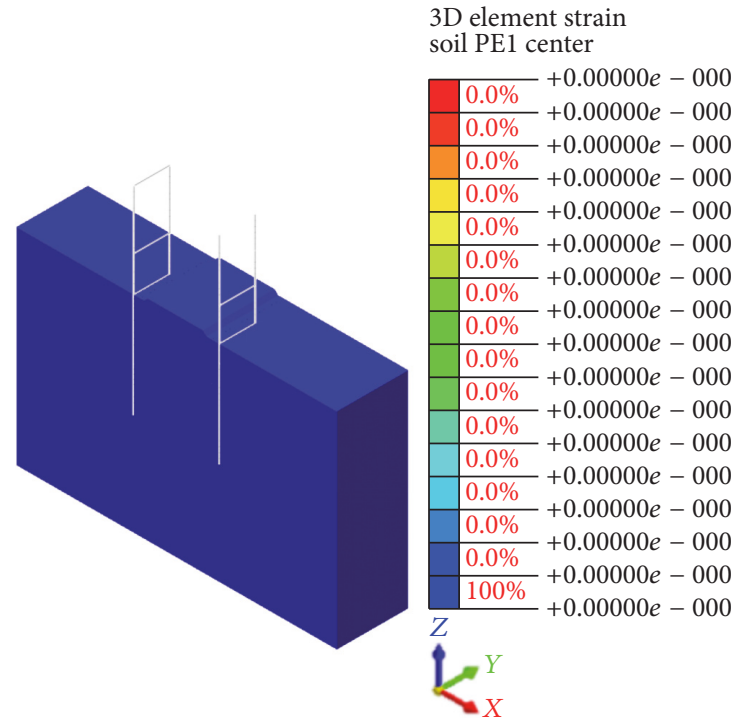

(a) Working conditions 1, 2

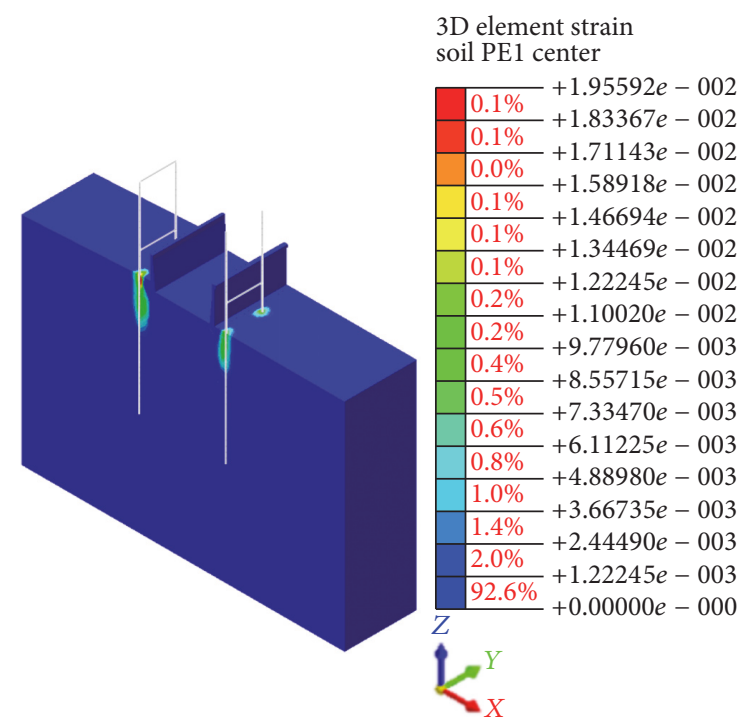

(c) Working condition 4

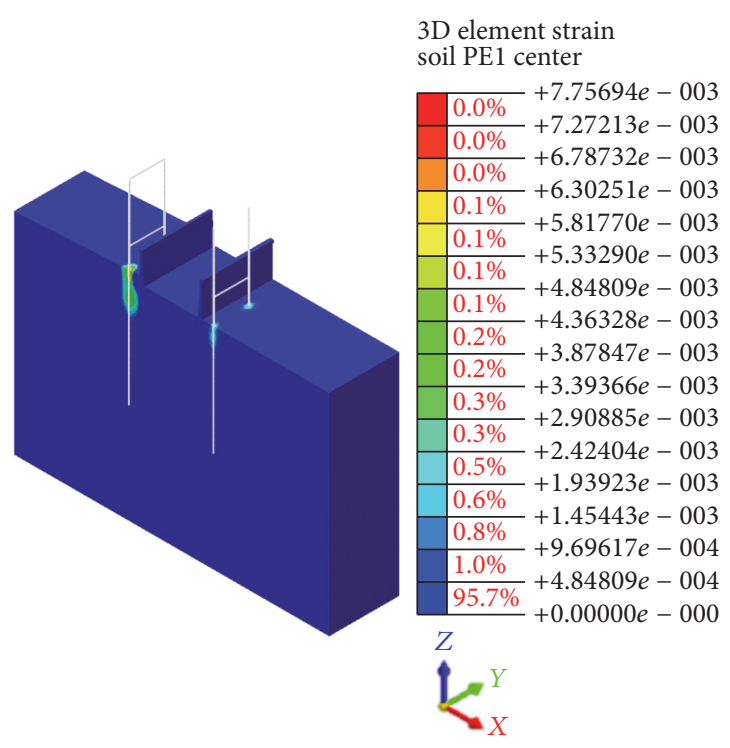

(b) Working condition 3

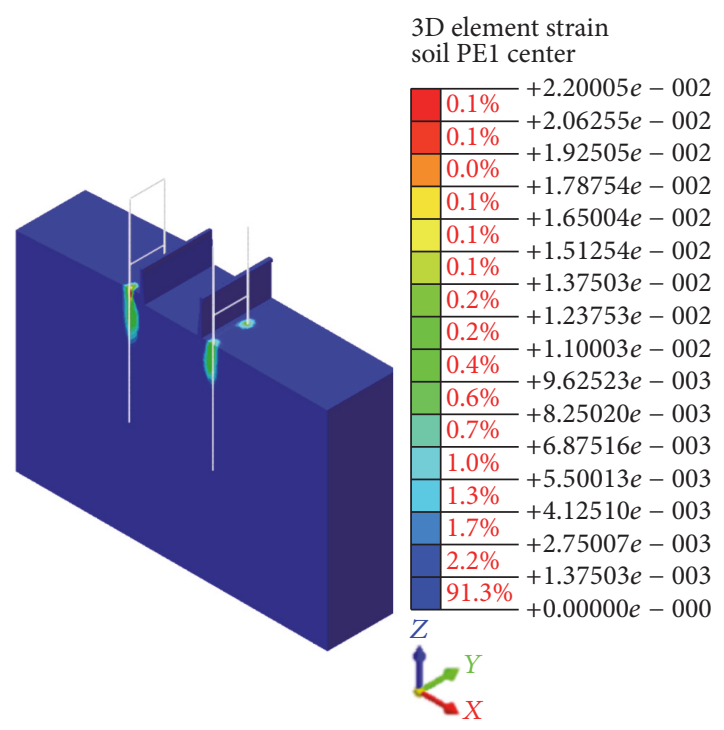

(d) Working condition 5

FIGURE 27: Maximum principal plastic strain of foundation soil under different working conditions.

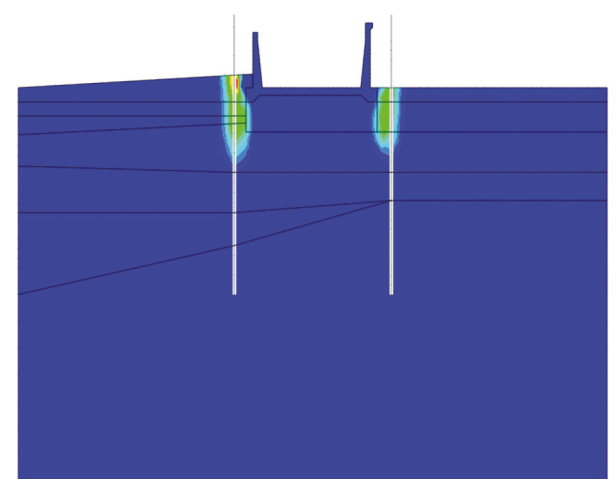

FIGURE 28: Maximum principal plastic strain of foundation soilvertical view.

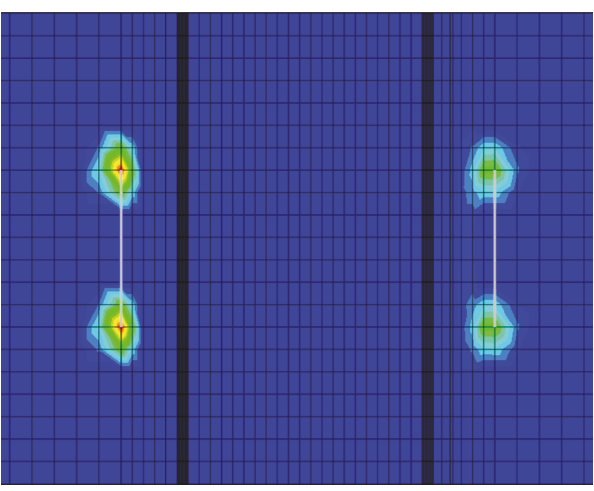

FIGURE 29: Maximum principal plastic strain of foundation soilplane view. 
(3) One to three cast-in-place piles connected with bridge piles by coupling beams are set at a certain interval along the construction direction of bridge outside the bridge pile.

\section{Conclusions}

(1) The lateral displacement of a pile foundation under stacking load is studied using MIDAS finite element software. Our findings showed that the lateral displacement of the pile foundation is positively correlated with stacking pressure and soft soil thickness but is negatively correlated with the deformation modulus of surface soil, the deformation modulus ratio of hard and soft soils, the pile diameter, and the axial force at the pile top. Lateral displacement has a significant nonlinear relationship with pile diameter and a linear relationship with the relative thickness of soft soil, which basically shows linear relations with other factors.

(2) Lateral displacement and axial force of bridge pile foundation in an actual engineering project during excavation and stacking loads are simulated by using finite element software. Numerical simulation results demonstrate that the lateral displacement resistance of the pile foundation is positively related to the rock-socketed depth of hard rock (soil). The lateral displacement of the pile foundation under different working conditions varies significantly. Stacking loads along piles not only causes lateral displacement of the pile body and the pile top but may also generate extranegative frictional resistance due to the compression of soil mass, thus increasing the axial force of the column bottom. Consequently, stacking loads along piles might cause pile damage, which deserves utmost attention. As a result of the lateral displacement of the pile body, soil mass along piles is damaged by compression, thereby causing a plastic zone, which weakens the lateral constraint of piles.

(3) With respect to large-scale actual engineering, a numerical simulation of complicated problems is conducted by using finite element software. The late construction is conducted according to the calculated values, which can achieve ideal results. In comparison with the empirical method and the in situ test, the proposed method exhibits outstanding speed, convenience, and accuracy. Therefore, the proposed method can be applied widely in actual engineering.

\section{Conflicts of Interest}

The authors declare that there are no conflicts of interest regarding the publication of this paper.

\section{Acknowledgments}

This work was supported by the National Natural Science Foundation of China (51679093 and 51774147), the Opening Fund of State Key Laboratory of Geohazard Prevention and Geoenvironment Protection (Chengdu University of Technology), China (SKLGP2018K008), the Natural Science Foundation of Fujian Province of China (2017J01094), and the Promotion Program for Young and Middle-Aged Teacher in Science and Technology Research of Huaqiao University, China (ZQN-PY112 and ZQN-PY311).

\section{References}

[1] F. Liang, F. Yu, and J. Han, "A simplified analytical method for response of an axially loaded pile group subjected to lateral soil movement," KSCE Journal of Civil Engineering, vol. 17, no. 2, pp. 368-376, 2013.

[2] H. G. Poulos, "Ground movements - a hidden source of loading on deep foundations," DFI Journal - The Journal of the Deep Foundations Institute, vol. 1, no. 1, pp. 37-53, 2014.

[3] T. Ito, T. Matsui, and W. P. Hong, "Design method for stabilizing piles against landslide - One row of piles," Soils \& Foundations, vol. 21, no. 1, pp. 21-37, 1981.

[4] T. Ito and T. Matsui, "Methods to estimate lateral force acting on stabilizing piles," Soils and Foundations, vol. 15, no. 4, pp. 43-59, 1975.

[5] T. L. Chen and H. G. Poulos, "Piles subjected to lateral soil movements," Journal of Geotechnical \& Geoenvironmental Engineering, vol. 123, no. 9, pp. 802-811, 1997.

[6] A. T. C. Goh, C. I. Teh, and K. S. Wong, "Analysis of piles subjected to embankment induced lateral soil movements," Journal of Geotechnical Engineering, vol. 123, no. 9, pp. 792-801, 1997.

[7] M. Ashour and G. Norris, "Modeling lateral soil-pile response based on soil-pile interaction," Journal of Geotechnical and Geoenvironmental Engineering, vol. 126, no. 5, pp. 420-428, 2000.

[8] C. LeBlanc, G. T. Houlsby, and B. W. Byrne, "Response of stiff piles in sand to long-term cyclic lateral loading," Géotechnique, vol. 60, no. 2, pp. 79-90, 2010.

[9] L. De Sanctis and G. Russo, "Analysis and performance of piled raft designed using innovative criteria," Journal of Geotechnical and Geoenvironmental Engineering, vol. 134, pp. 1118-1128, 2008.

[10] P. Kitiyodom and T. Matsumoto, "A simplified analysis method for piled raft foundations in non-homogeneous soils," International Journal for Numerical and Analytical Methods in Geomechanics, vol. 27, no. 2, pp. 85-109, 2003.

[11] S. Karthigeyan, G. S. T. V. Ramakrishna, and K. Rajagopal, "Influence of vertical load on the lateral response of piles in sand," Computers \& Geotechnics, vol. 33, no. 2, pp. 121-131, 2006.

[12] C. J. Chien, S. S. Lin, C. C. Yang, and J. C. Liao, "Lateral performance of drilled shafts due to combined lateral and axial loading," Journal of Mechanics, vol. 29, no. 4, pp. 685-693, 2013.

[13] J. Lee, M. Prezzi, and R. Salgado, "Influence of axial loads on the lateral capacity of instrumented steel model piles," International Journal of Pavement Research and Technology, vol. 6, no. 2, pp. 80-85, 2013.

[14] L. Mu, M. Huang, and K. Lian, "Analysis of pile-raft foundations under complex loads in layered soils," International Journal for Numerical and Analytical Methods in Geomechanics, vol. 38, no. 3, pp. 256-280, 2014.

[15] L. Mu, X. Kang, K. Feng, M. Huang, and J. Cao, "Influence of vertical loads on lateral behaviour of monopiles in sand," European Journal of Environmental and Civil Engineering, pp. $1-16,2017$.

[16] M. Ashour, P. Pilling, and G. Norris, "Lateral behavior of pile groups in layered soils," Journal of Geotechnical and Geoenvironmental Engineering, vol. 130, no. 6, pp. 580-592, 2004.

[17] Z. Yang and J. Boris, "Numerical analysis of pile behaviour under lateral loads in layered elastic-plastic soils," International Journal for Numerical and Analytical Methods in Geomechanics, vol. 26, no. 14, pp. 1385-1406, 2002. 
[18] Z.-D. Jing, L. Liu, G. Zheng, and Y. Jiang, "Numerical analysis of pile lateral behavior of pile supported embankment," Journal of Central South University of Technology (English Edition), vol. 15, no. 2, pp. 87-92, 2008.

[19] W. D. Guo and E. H. Ghee, Tall Buildings, World Scientific Connecting Minds, 2015.

[20] K. M. Reddy and R. Ayothiraman, "Experimental studies on behavior of single pile under combined uplift and lateral loading," Journal of Geotechnical and Geoenvironmental Engineering, vol. 141, no. 7, Article ID 04015030, 2015.

[21] L. Hazzar, M. N. Hussien, and M. Karray, "Numerical investigation of the lateral response of battered pile foundations," International Journal of Geotechnical Engineering, vol. 11, no. 4, pp. 376-392, 2016.

[22] Y. Zhang, Y. M. Abufarsakh, and G. Z. Voyiadjis, "Finite Element Analysis of a Laterally Loaded Battered Pile Group Foundation," in Proceedings of the Transportation Research Board 94th Annual Meeting, 2015.

[23] Y. Zhang, "Numerical Study of Laterally Loaded Batter Pile Groups with the Application of Anisotropic Modified CamClay Model," 2012.

[24] A. Souri, M. Abu-Farsakh, and G. Voyiadjis, "Study of static lateral behavior of battered pile group foundation at I-10 Twin Span Bridge using three-dimensional finite element modeling," Canadian Geotechnical Journal, vol. 53, no. 6, pp. 962-973, 2015.

[25] C. Y. Chen and H. Q. Hsu, "Modeling of Batter Pile Behavior under Lateral Soil Movement," in Proceedings of the 2017 2nd International Conference on Civil Engineering and Materials Science, ICCEMS 2017, vol. 216, IOP Publishing, Republic of Korea, 2017.

[26] Z.-F. Zhang and J.-P. Li, "Analysis of piles subject to axial load and lateral soil movement," Advanced Materials Research, vol. 383-390, pp. 1708-1713, 2012.

[27] Y. Choi, G. Kim, O. Kwon et al., "Effect of bedrock depth on the lateral behavior of monopiles," Geo-Shanghai, pp. 191-197, 2014.

[28] R. Karimm, Los. C. R., and T. Gnanendranc, "Behaviour of piles subjected to passive loading due to embankment cons," Revue Canadienne De Géotechnique, vol. 51, no. 3, pp. 303-310, 2014. 


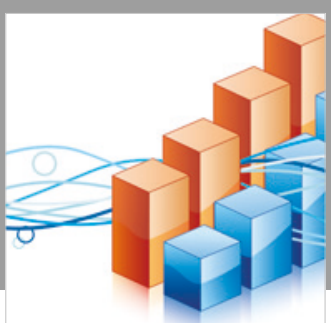

Advances in

Operations Research

\section{-n-m}
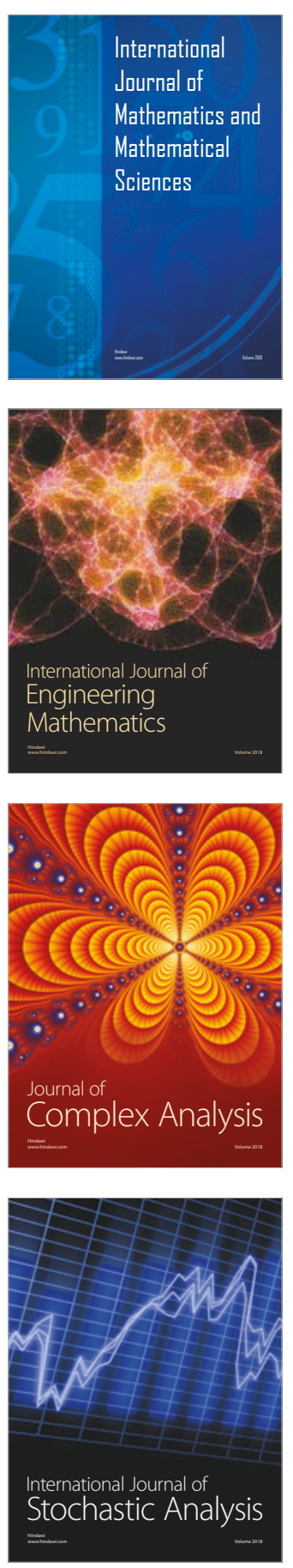
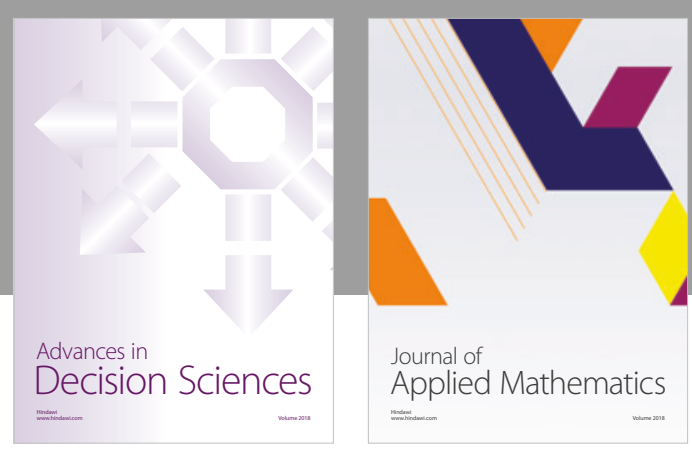

Journal of

Applied Mathematics
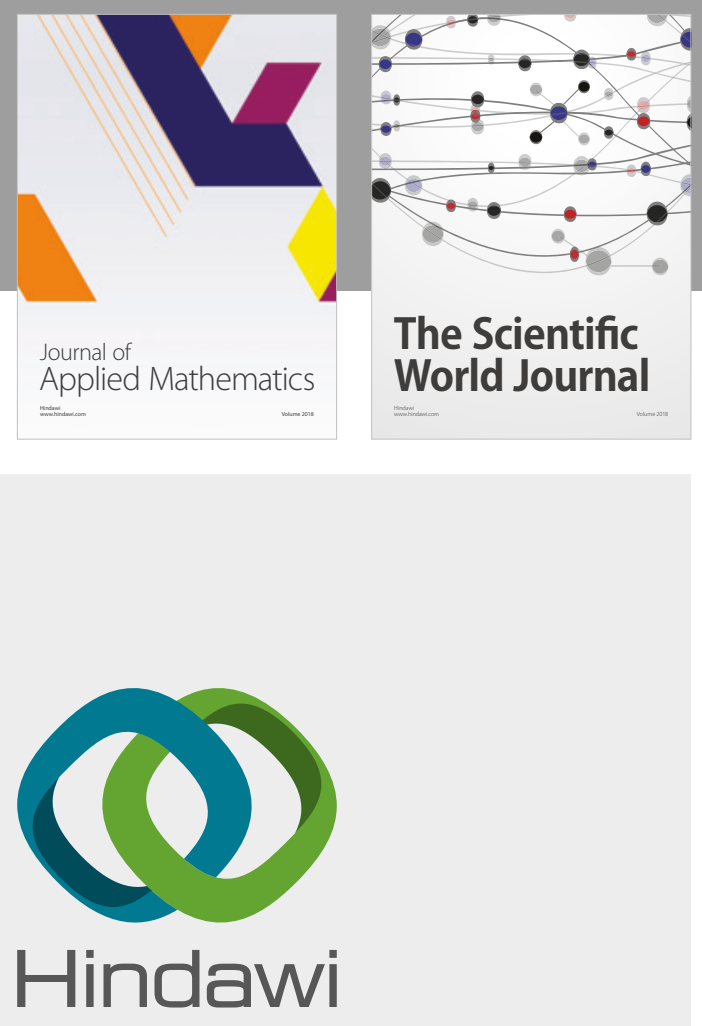

Submit your manuscripts at

www.hindawi.com

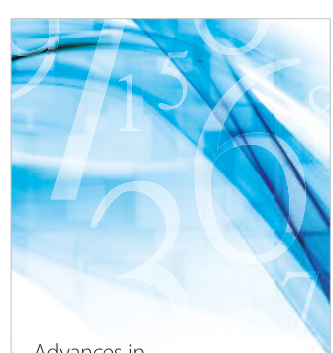

Advances in
Numerical Analysis
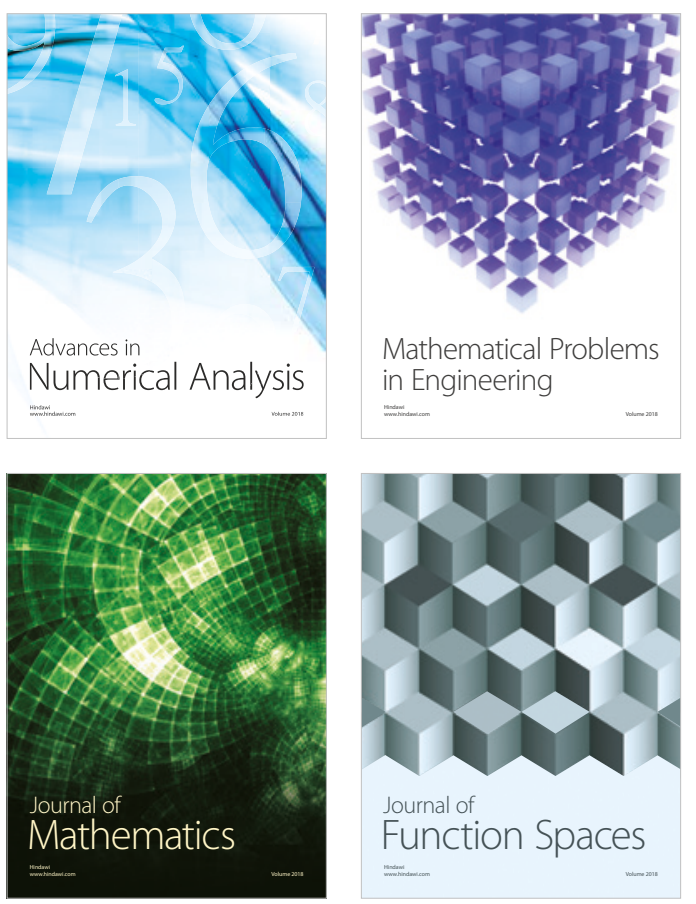

Mathematical Problems in Engineering

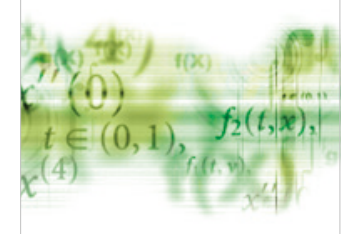

International Journal of

Differential Equations

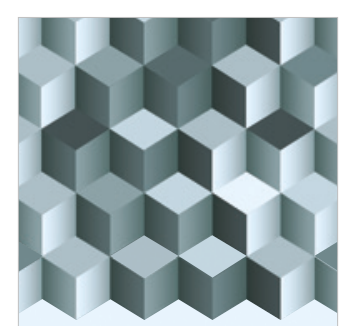

Journal of

Function Spaces
The Scientific

World Journal

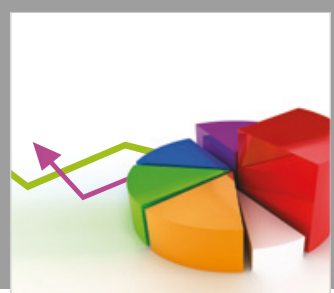

Journal of

Probability and Statistics
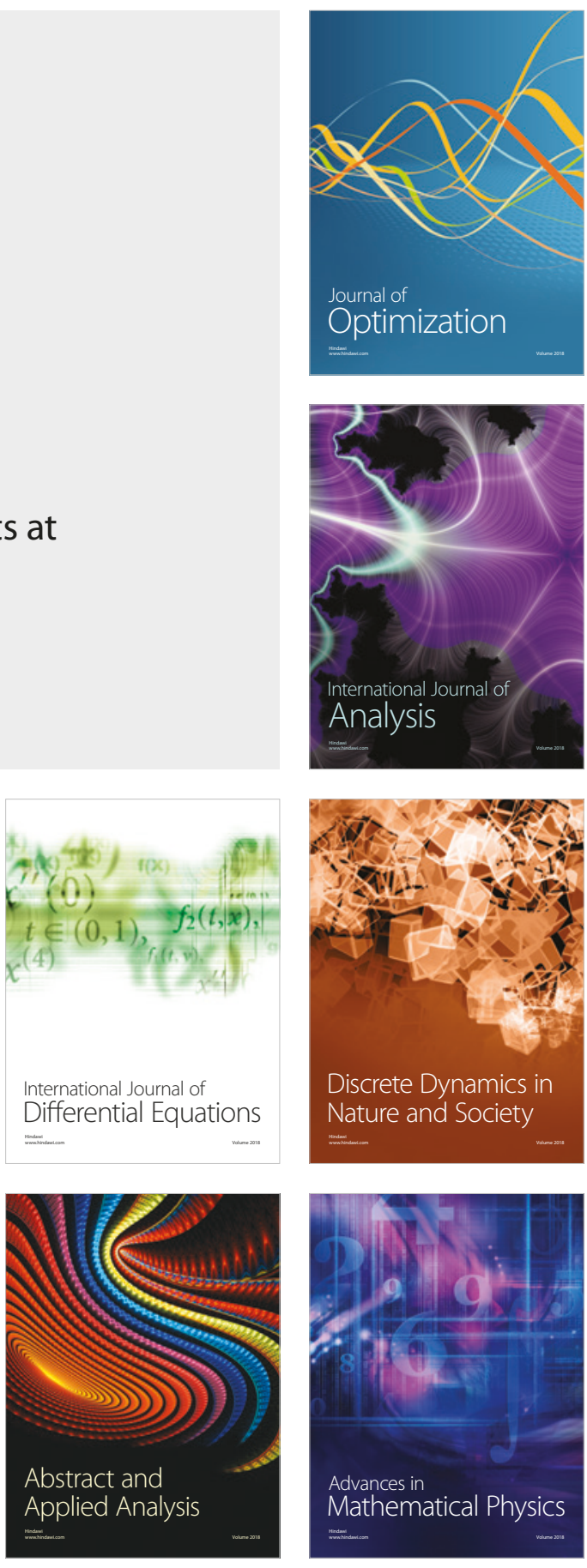